Behavioural pharmacology

\title{
Very low doses of muscimol and baclofen ameliorate cognitive deficits and regulate protein expression in the brain of a rat model of streptozocin- induced Alzheimer's disease
}

\author{
Vladimirs Pilipenko*, Karina Narbute, Ulrika Beitnere, Juris Rumaks, Jolanta Pupure, \\ Baiba Jansone, Vija Klusa
}

Department of Pharmacology, Faculty of Medicine, University of Latvia, 1 Jelgavas St., LV-1004 Riga, Latvia

\section{A R T I C L E I N F O}

\section{Keywords:}

Rat model of $\mathrm{AD}$

STZ

Muscimol

Baclofen

Learning

Memory

\begin{abstract}
A B S T R A C T
Recent studies devoted to neuroprotection have focused on the role of the gamma-aminobutyric acid (GABA) system in regulating neuroinflammatory processes which play a key role in the neurodegenerative processes observed in Alzheimer's disease (AD) by inducing glial cell overactivation and impairing neurotransmission.

Data on the efficacy of classical GABA-A and GABA-B receptor agonists (muscimol and baclofen, respectively) in animal models of AD are not available. Moreover, no published studies have examined the ability of optimal doses of these compounds to prevent neuroinflammation, the alterations in neurotransmission and cognitive deficits. In the present study, we used a non-transgenic rat model of AD obtained by intracerebroventricular streptozocin (STZ) injection and assessed the effects of muscimol and baclofen at very low doses $(0.01-0.05 \mathrm{mg} /$ $\mathrm{kg}$ ) on spatial memory and the expression of cortical and hippocampal proteins related to neuroinflammation, namely proteins involved in astroglial functions (glial fibrillary acidic protein, GFAP), GABA synthesis (GABA synthesizing enzyme, glutamic acid decarboxylase 67, GAD67) and acetylcholine degradation (acetylcholine esterase).

The presented study demonstrated that in a rat model of STZ-induced AD both muscimol and baclofen at the tested doses exerted memory-enhancing and anti-inflammatory effects, as well as normalization of acetylcholine esterase and GABA expression. We suggested that the function of very low doses of GABA receptor agonists differs from typical GABA-related inhibition and may be mediated by the allosteric sites of GABA receptors or other non-specific cell regulatory pathways.
\end{abstract}

\section{Introduction}

Alzheimer's disease (AD) has multifactorial pathology. Accumulation of extracellular amyloid-beta $(\mathrm{A})$ plaques and intracellular neurofibrillary tangles comprising the hyperphosphorylated tau protein (Mendiola-Precoma et al., 2016), as well as neuroinflammation, play key roles in the neurodegenerative processes observed in AD (Buckwalter and Wyss-Coray, 2004; McManus and Heneka, 2017). Neuroinflammation occurs by increased activation of microglia (Calsolaro and Edison, 2016; McNaull et al., 2010; Southam et al., 2016) and macroglia (Chen et al., 2012; Verkhratsky et al., 2016), initiation of a pathological cascade that includes oxidative stress, mitochondrial dysfunction (Correia et al., 2016) and activation of the vitagene system (genes that modulate redox-dependent mechanisms) (Calabrese et al., 2010; Trovato-Salinaro et al., 2016). Thus, the identification of a new treatment strategy that halts neurodegenerative events and synaptic dysfunction at the early pre-dementia stage of $\mathrm{AD}$ by maintaining a balance between excitatory and inhibitory neurotransmitter systems constitutes a promising therapeutic approach for AD treatment (Calsolaro and Edison, 2016; Nava-Mesa et al., 2014; Palop and Lennart, 2010).

Previous studies devoted to examining neuroprotection and memory-improving drugs were primarily focused on cholinergic (Deiana et al., 2011) and glutamatergic (Butterfield and Pocernich, 2003) systems, whereas less attention was paid to the gamma-aminobutyric acid (GABA) system. However, this system has recently been highlighted, stressing its compensatory role in memory formation (Lanctôt et al., 2004; Obata, 2013; Oren et al., 2006; Zemankovics et al., 2013), which is perturbed in the early stages of neurodegeneration (Nava-Mesa et al., 2014). The dysfunction of GABAergic pathways (Limon et al., 2012; Paula-Lima et al., 2005) and the loss of hippocampal GABAergic neurons (Krantic et al., 2012) are strongly

\footnotetext{
* Corresponding author

E-mail address: vladimirs.pilipenko@lu.lv (V. Pilipenko).
} 


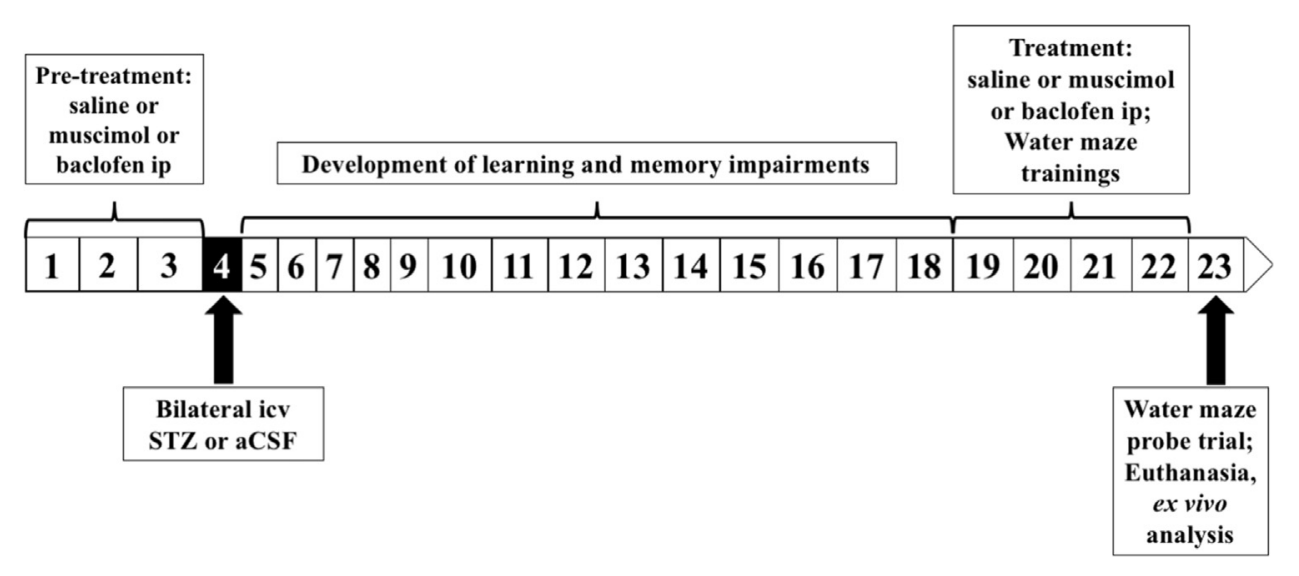

Fig. 1. Experimental design of the present study.

implicated to participate in $\mathrm{AD}$ pathogenesis, particularly in memory impairments. Based on accumulating data, GABAergic activities are closely associated with immune processes; brain glial cells contain GABA receptors and may release a considerable amount of GABA that may also function as a gliotransmitter (Crowley et al., 2016; Yoon and Lee, 2014). A deficiency in GABA receptor activity leads to the initiation of neuroinflammatory signaling pathways, and reciprocally, GABAergic signaling affects neuroinflammatory processes through its antiinflammatory activities (Crowley et al., 2016).

Previous studies describing the effects of GABA-A and GABA-B receptor agonists (used at $1-10 \mathrm{mg} / \mathrm{kg}$ ) have reported impaired cognitive responses (Castellano et al., 1989; Castellano and McGaugh, 1990; Swartzwelder et al., 1987). For example, at 1 and $2 \mathrm{mg} / \mathrm{kg}$, muscimol negatively affected memory storage processes in mice (Castellano and McGaugh, 1990), whereas 5 and $10 \mathrm{mg} / \mathrm{kg}$ baclofen disrupted memory retention in rats performing the passive avoidance task (Swartzwelder et al., 1987). Intriguingly, the recent study by Ding et al. (2015) showed that the administration of a 10 -fold lower dose $(0.1 \mathrm{mg} / \mathrm{kg}$, ip) of muscimol to rats protected the hippocampus from apoptosis, prevented learning/memory dysfunctions, decreased astroglial activation and increased synaptic plasticity. Considering the complexity of GABA synthesis and receptor sites, we suggested that very low doses of GABA receptor agonists might act through mechanisms which differ from that of high doses, and their effects may be mediated by the allosteric sites of GABA receptors or other non-specific cell regulating pathways. In the present study, we used a non-transgenic rat model of $\mathrm{AD}$ obtained through an intracerebroventricular (icv) injection of streptozocin (STZ) and assessed the effects of very low doses (100-fold lower than the mostly used $1 \mathrm{mg} / \mathrm{kg}$ ) of muscimol $(0.01$ and $0.05 \mathrm{mg} / \mathrm{kg})$ and baclofen ( 0.025 and $0.05 \mathrm{mg} / \mathrm{kg}$ ) on spatial learning/memory (water maze), the expression of cortical and hippocampal proteins related to neuroinflammation, namely astroglial function, as well as GABA synthesis and acetylcholine degradation.

\section{Materials and methods}

\subsection{Chemicals and antibodies}

The following chemicals were obtained from Sigma-Aldrich (USA): 3,3'-diaminobenzidine (DAB, D5905), anti-GFAP antibody (G3893), ethopropazine (E5406), ExtrAvidin Peroxidase Staining Kit (EXTRA2), hematoxylin solution (MHS16), muscimol (M1523), and streptozocin (S0130). The anti-GAD67 antibody (sc-28376) was obtained from Santa Cruz Biotechnology (USA). S-Acetylthiocholine iodide (A16802) was obtained from Alfa Aesar (USA). Copper sulfate (102,790), potassium hexacyanoferrate (III) $(104,973)$, and sodium citrate $(106,448)$ were obtained from Merck-Millipore (USA). Artificial cerebrospinal fluid (aCSF) was prepared ex tempore.

\subsection{Animals}

Male Wistar rats $(280 \pm 20 \mathrm{~g})$ were obtained from the Laboratory of Experimental Animals, Riga Stradins University, Riga, Latvia. All efforts were made to minimize animal suffering and reduce the number of animals used. The experiments were conducted in accordance with the EU Directive 2010/63/EU and local laws and policies on the protection of animals used for scientific purposes. The animal protocol used in the present study was approved by the Animal Ethics Committee of the Food and Veterinary Service, Riga, Latvia. The animals were housed in polypropylene cages (5 rats per cage) with food (R70, Lantmännen, Sweden) and tap water provided ad libitum in a controlled laboratory environment (temperature $22 \pm 2{ }^{\circ} \mathrm{C}$, humidity 50-60\%, $12 \mathrm{~h}$ light/ dark cycle).

\subsection{Experimental design}

\subsubsection{Treatment with muscimol and baclofen}

The experimental design of the present study is shown in Fig. 1. The rats were randomly divided into six groups of 10 animals each. The groups received intraperitoneal (ip) injections of either saline (SAL, $1 \mathrm{ml} / \mathrm{kg}$ ), muscimol (M, 0.01 and $0.05 \mathrm{mg} / \mathrm{kg}$, dissolved in saline) or baclofen (BCL, 0.025 and $0.05 \mathrm{mg} / \mathrm{kg}$, dissolved in saline) for $3 \mathrm{con}$ secutive days prior to the icv injection of STZ or artificial cerebrospinal fluid (aCSF) and during 4 consecutive water maze training days (30 min prior to the test). The following groups were used in the muscimol experiments: 1) SAL + aCSF (control group); 2) SAL + STZ (lesion group); 3) M 0.01 + STZ; 4) M 0.05 + STZ; 5) M 0.01 + aCSF; and 6) M 0.05 + aCSF. In the baclofen experiments, the groups were: 1) SAL + aCSF (control group); 2) SAL + STZ (lesion group); 3) BCL 0.025 + STZ; 4) BCL 0.05 + STZ; 5) BCL 0.025 + aCSF; and 6) BCL $0.05+$ aCSF.

\subsubsection{Surgery}

On experimental day 4 , the animals were anesthetized using a ketamine and xylazine mixture (75 and $10 \mathrm{mg} / \mathrm{kg}$, ip, respectively) and placed on a stereotaxic frame (Stoelting Inc., USA). A midline sagittal incision was made and two holes were drilled in the skull. STZ dissolved in $\operatorname{aCSF}(750 \mu \mathrm{g} / 10 \mu \mathrm{l})$ was injected into both lateral ventricles using the following coordinates (Paxinos and Watson, 2007): $-0.7 \mathrm{~mm}$ anteroposterior, $1.7 \mathrm{~mm}$ mediolateral, and $-4.0 \mathrm{~mm}$ dorsoventral relative to the bregma using a Hamilton microsyringe $(1 \mu \mathrm{l} / \mathrm{min})$. Control groups received bilateral injections of aCSF. The microsyringe was left in place for $5 \mathrm{~min}$ after each injection to allow the drug to diffuse.

\subsubsection{Morris water maze test}

The water maze test was performed 14 days after the STZ injection (on experimental days 19-23) to examine the rats' spatial learning and memory. A blue circular tank ( $d=180 \mathrm{~cm}$, Ugo Basile, Italy) was filled 


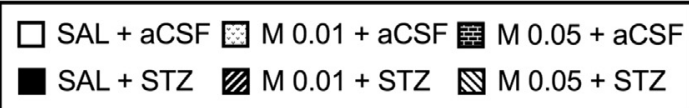

A

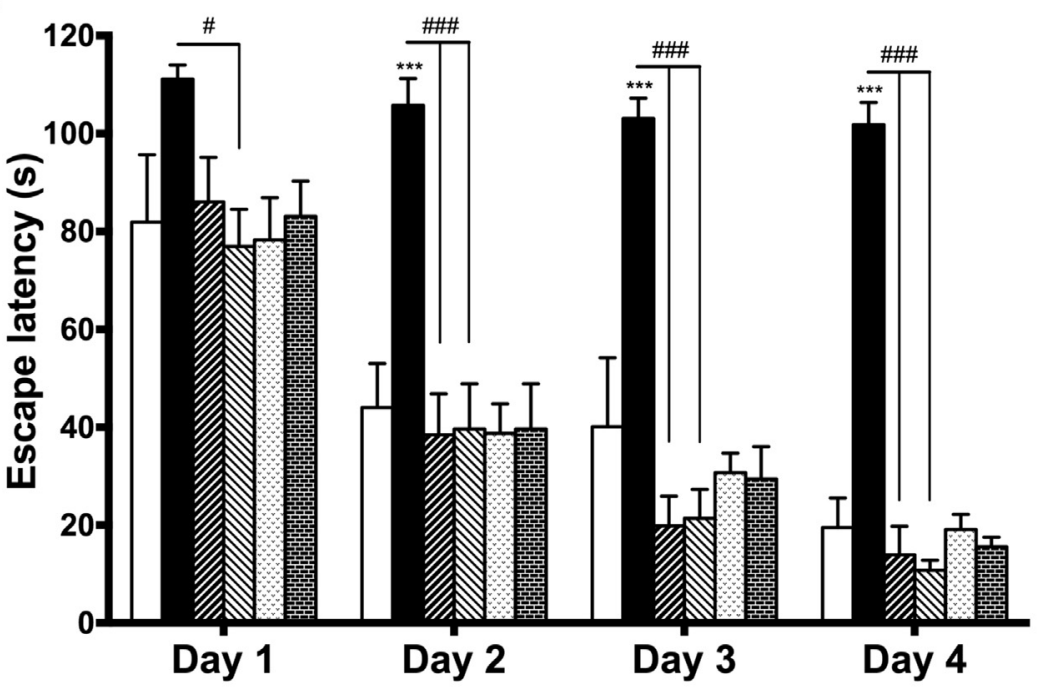

B
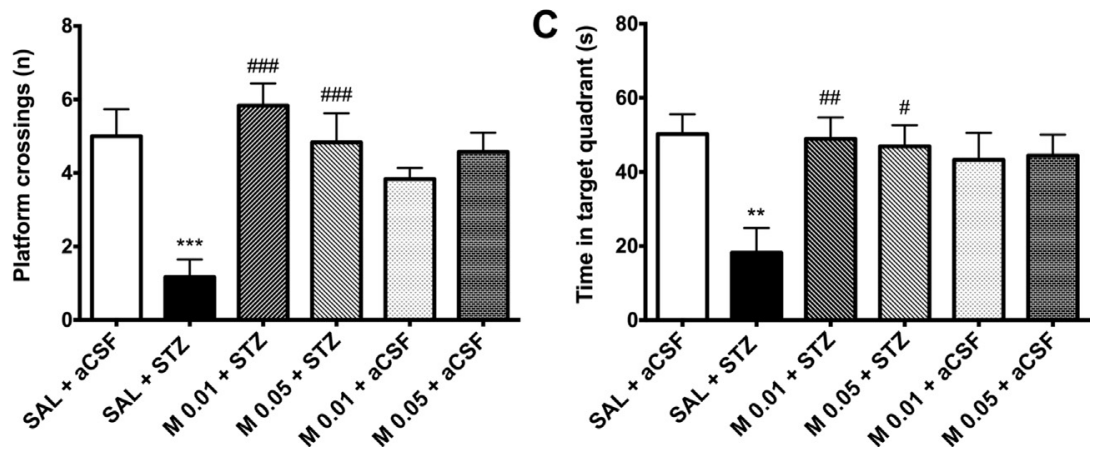

Fig. 2. Effect of muscimol (M) on rat performance in the Morris water maze test. Rats were icv injected with STZ or aCSF and ip injected with $\mathrm{M}(0.01$ and $0.05 \mathrm{mg} / \mathrm{kg})$ or saline. Spatial learning is shown as the mean escape latency on each training day (A). Spatial memory in the probe trial is shown as the number of platform crossings (B) and cumulative time spent in the platform quadrant (C). The data are presented as the means \pm S.E.M. $* * P<0.01$ and $* * * P<0.001$ compared with the aCSF group; $\# P<0.05$, \#\#P $<0.01$ and \#\#\#P $<0.001$ compared with the STZ group. Repeated measures two-way ANOVA followed by Bonferroni's multiple comparison test. with water $\left(22 \pm 1{ }^{\circ} \mathrm{C}\right)$ to a depth of $30 \mathrm{~cm}$. The rats were trained to swim from each of the 4 starting points in the pool and find the hidden platform that was fixed and submerged in one of the quadrants below the water level $(1 \mathrm{~cm})$ using 4 trials per day for 4 consecutive days (120 s for each trial). The rats were gently placed in the water facing the wall of the pool. Immediately upon finding the platform, the rat was allowed to remain on the platform for $10 \mathrm{~s}$ to learn the location. If the platform was not found, the experimenter gently guided the animal to the platform and allowed it to remain there for $10 \mathrm{~s}$. The latency to find the hidden platform (escape latency) and swimming speed were documented. On experimental day 23 , the probe test was performed. Briefly, the platform was removed from the pool, and each animal received one $120 \mathrm{~s}$ trial in the water maze task. The time spent in the target quadrant, number of platform zone crossings and swimming speed were documented. The experiments were performed from 9:00 until 15:00. Video-tracking software (EthoVision XT 9.0 by Noldus, NL) was used to register the above-mentioned parameters.

\subsubsection{Immunohistochemistry}

Immediately after the probe test, the rats were deeply anesthetized with a ketamine/xylazine $(100 / 10 \mathrm{mg} / \mathrm{kg})$ mixture and transcardially perfused with cold saline. The brains were removed and fixed in $4 \%$ paraformaldehyde for $24 \mathrm{~h}$. After fixation, the brains were placed in $30 \%$ sucrose for $48 \mathrm{~h}$ for cryoprotection and subsequently placed in an antifreeze solution.

For each brain, coronal slices ( $30 \mu \mathrm{m}$ thick) were obtained using a cryotome (CM1850, Leica Biosystems, USA). The slices were incubated in citrate buffer (pH 6.0) at high temperature $\left(95^{\circ} \mathrm{C}\right)$ for $10 \mathrm{~min}$, subsequently cooled to room temperature and blocked with a $5 \%$ bovine serum albumin (BSA) solution for $30 \mathrm{~min}$ to improve antigen retrieval. Free-floating sections were then stained with primary antibodies. The sections were transferred to a solution containing the primary antibody in phosphate buffered saline (PBS) with $0.5 \%$ Triton X-100 (PBS-T). After an $18 \mathrm{~h}$ incubation in the antibody diluted in PBS-T at room temperature, the sections were rinsed 3 times with PBS-T and transferred to a solution containing the secondary antibody (dilution 1:500). After a $2 \mathrm{~h}$ incubation with the secondary antibody, the sections were rinsed three times with PBS-T and transferred to PBS-T containing mouse ExtrAvidin Peroxidase (1:1000) for $2 \mathrm{~h}$. After rinsing, the sections were incubated with PBS-T containing DAB for 1 min. All stained sections were mounted on gelatin-coated slides and coverslipped.

\subsubsection{Histochemistry}

Histochemical detection of acetycholine esterase was performed using a previously described method (Karnovsky and Roots, 1964), which was optimized and described elsewhere (Kadish and Van Groen, 2002). Briefly, brain sections were rinsed with a $0.1 \mathrm{M}$ maleate buffer ( $\mathrm{pH}$ 6.0). Subsequently, the sections were incubated with $0.1 \mathrm{M}$ maleate buffer containing $86.5 \mathrm{mM}$ S-acetylthiocholine iodide, $30 \mathrm{mM}$ ethopropazine, $30 \mathrm{mM}$ copper sulfate, and $100 \mathrm{mM}$ sodium citrate and $0.03 \mathrm{mM}$ potassium hexacyanoferrate for $2 \mathrm{~h}$. Subsequently, the staining was intensified by incubating the sections with $0.04 \%$ DAB and $0.02 \%$ hydrogen peroxide in $0.05 \mathrm{M}$ Tris buffer $(\mathrm{pH} 7.6)$ for $2 \mathrm{~min}$. 


\subsubsection{Quantification}

The mounted brain sections were scanned using a Pannoramic Midi II Scanner (3DHISTECH, USA) at $200 \times$ magnification. The optical density of glial GFAP, neuronal GAD67 and nerve fiber acetycholine esterase staining in the anterior cingulate cortex and stratum radiatum of hippocampal CA1 was measured. An observer blinded to the treatment of the animals performed all measurements in duplicate using ImageJ software. Three sections from each brain were analyzed in one session.

\subsubsection{Statistical analysis}

All data are presented as the means \pm standard errors of the means (S.E.M.) values. Inter-group variations (Group and Training Day as factors) in escape latency data of the water maze were detected by twoway analysis of variance (ANOVA) with repeated measures followed by Bonferroni's multiple comparisons test. Water maze probe test data, as well as quantitative immunohistochemical and histochemical data were analyzed using one-way ANOVA followed by Bonferroni's multiple comparison test. Graph Pad Prism ${ }^{\circledR}$ software version 6.0 (Graph Pad Software, Inc., USA) was used for data analysis.

\section{Results}

\subsection{Effects of muscimol and baclofen on spatial learning and memory}

The performance of rats that were icv injected with STZ and ip injected with $\mathrm{M}(0.01$ and $0.05 \mathrm{mg} / \mathrm{kg}$ ) or saline in the Morris water maze test is shown in Fig. 2. Differences in groups $\left(\mathrm{F}_{5,35}=26.69, P<0.001\right)$, training days $\left(\mathrm{F}_{3,105}=94.41, P<0.001\right)$ and between groups and days $\left(\mathrm{F}_{15,105}=2.99, P<0.001\right)$ were observed. The administration of STZ resulted in a longer escape latency than that of the controls starting from training day $2(P<0.001)$. Treatment with $0.05 \mathrm{mg} / \mathrm{kg}$ muscimol shortened the escape latency of STZ-injected rats already from the training day $1(P<0.001)$, whereas muscimol at $0.01 \mathrm{mg} / \mathrm{kg}$ showed this effect starting from training day 2 . In the probe trial, differences between groups were observed in platform crossings $\left(F_{5,31}=7.32\right.$, $P<0.001$, Fig. 2B) and in the time spent in the target quadrant $\left(\mathrm{F}_{5,33}\right.$ $=3.53, P=0.012$, Fig. $2 \mathrm{C}$ ). STZ also produced impairments in spatial memory via decrease in platform crossings $(P<0.001)$ and time spent in the target quadrant $(P<0.01)$ compared to controls. Muscimoltreated STZ group rats showed a reversal of the STZ-induced impairments by demonstrating an increase in the number of platform crossings $(P<0.001)$ and time spent in the target quadrant $(P<0.001)$. No significant differences in swimming speed were observed between groups on all training days (data not shown).

Fig. 3 shows the performance of rats that were icv injected with STZ or aCSF and ip injected with BCL $(0.025$ and $0.05 \mathrm{mg} / \mathrm{kg})$ or saline in the Morris water maze test. There was a difference in groups $\left(\mathrm{F}_{5,37}=\right.$ 13.61, $P<0.001)$, training days $\left(\mathrm{F}_{3,111}=66.14, P<0.001\right)$ and between groups and days $\left(F_{15,111}=3.26, P<0.001\right)$. The administration of baclofen in $0.05 \mathrm{mg} / \mathrm{kg}$ dose prevented the STZ-induced spatial learning impairments from training day 1 , whereas the $0.025 \mathrm{mg} / \mathrm{kg}$ dose produced similar effect on training days 2-4. In the probe test, differences between groups were observed in platform crossings $\left(\mathrm{F}_{5,30}\right.$ $=5.40, P=0.0012$, Fig. $3 \mathrm{~B})$ and in the time spent in the target quadrant $\left(\mathrm{F}_{5,30}=5.81, P<0.001\right.$, Fig. $\left.3 \mathrm{C}\right)$. STZ-injected rats that were treated with either dose of baclofen displayed a significant increase in the number of platform crossings $(P<0.05)$ and the time spent in the target quadrant $(P<0.01)$. No significant differences in swimming speed were observed between groups in all training days (data not shown).

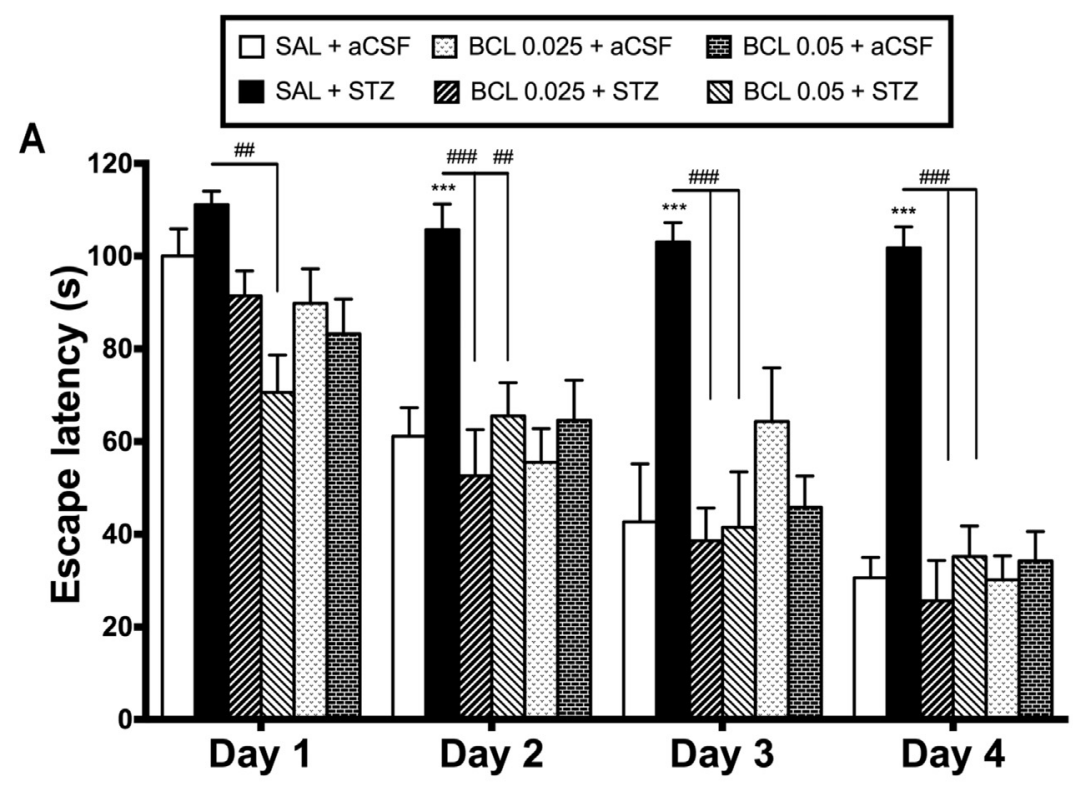

Fig. 3. Effect of baclofen (BCL) on rat performance in the Morris water maze test. Rats were icv injected with STZ or aCSF and ip injected with BCL $(0.025$ and $0.05 \mathrm{mg} / \mathrm{kg})$ or saline. Spatial learning is shown as the mean escape latency on each training day (A). Spatial memory in the probe trial is shown as the number of platform crossings (B) and cumulative time spent in the platform quadrant $(\mathrm{C})$. The data are presented as the means \pm S.E.M. $* * P<0.01$ and $* * * P<0.001$ compared with the aCSF group;

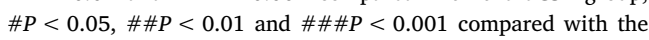
STZ group. Repeated measures two-way ANOVA followed by Bonferroni's multiple comparison test.
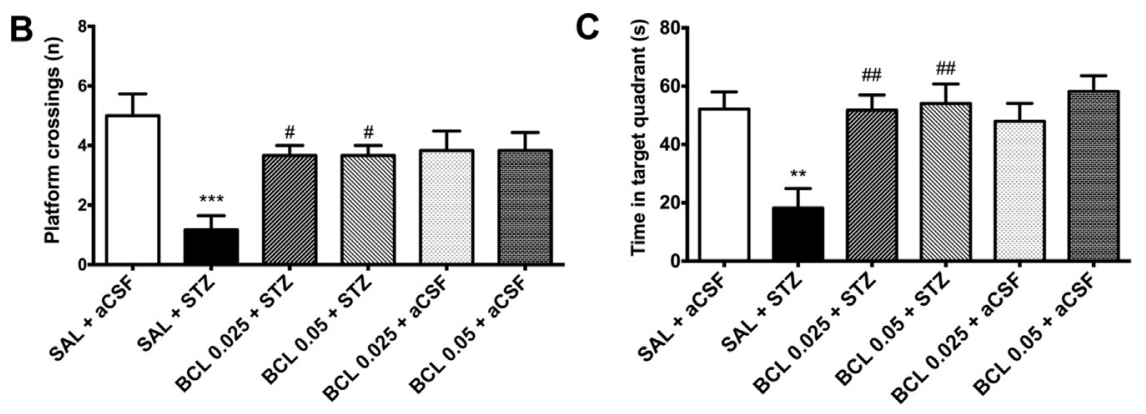

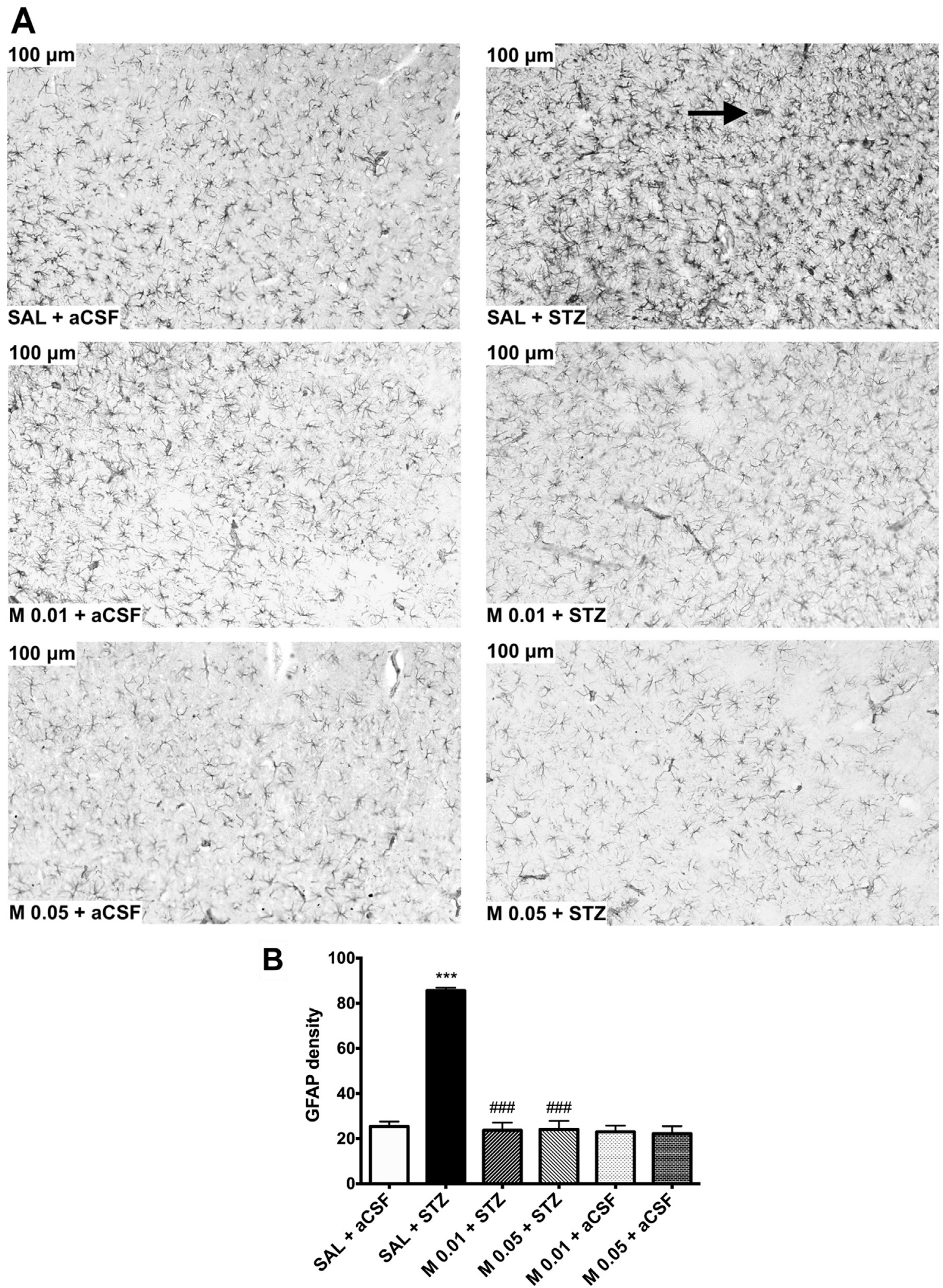

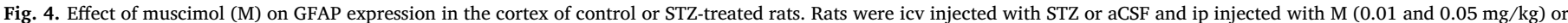

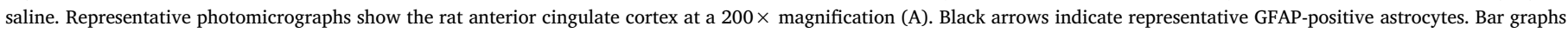

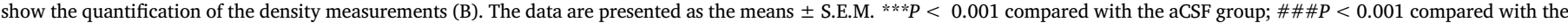
STZ group. One-way ANOVA followed by Bonferroni's multiple comparison test. 

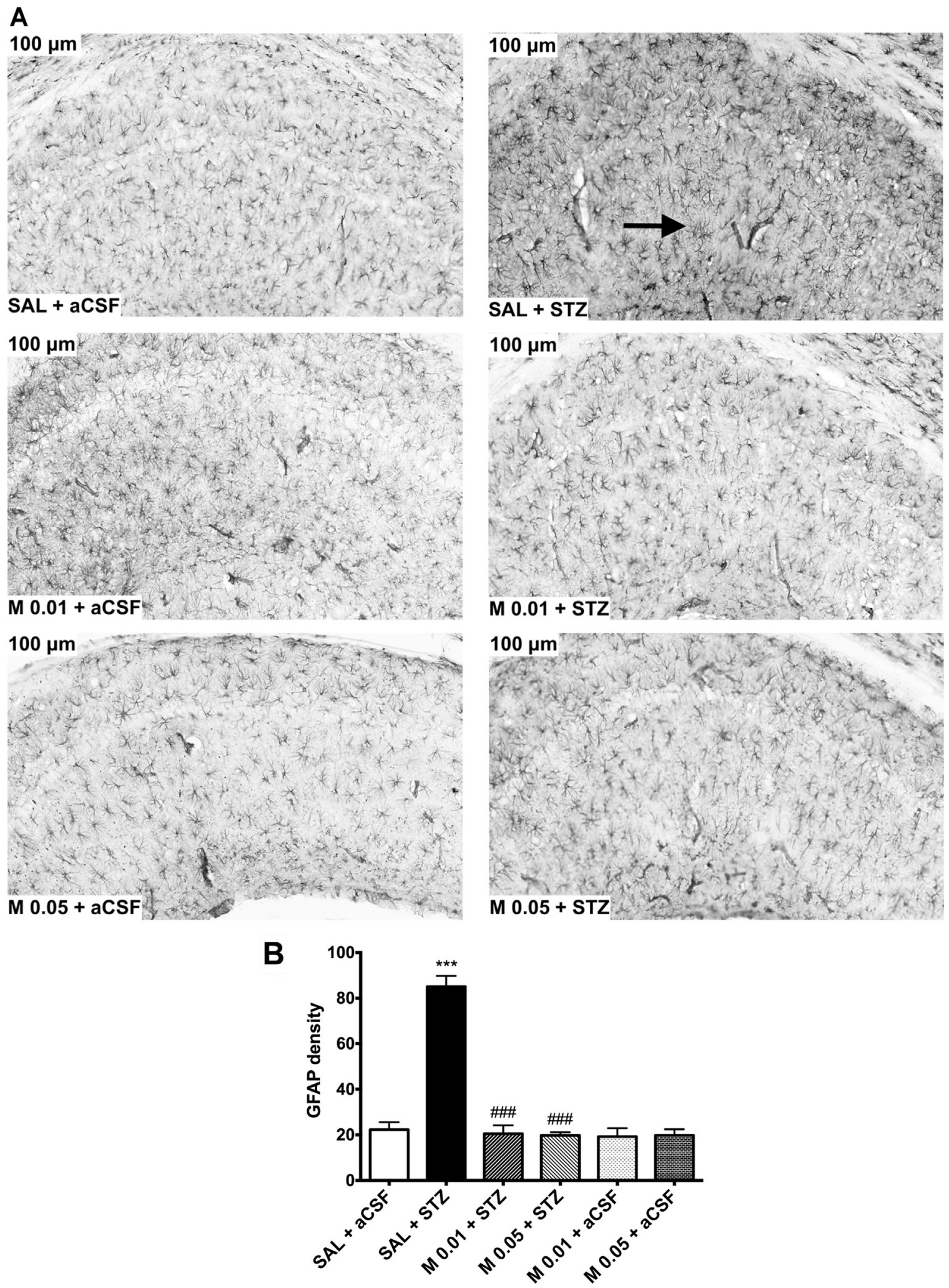

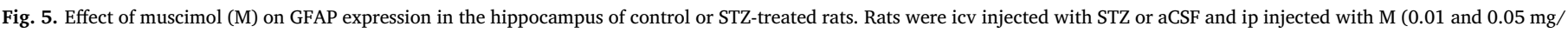

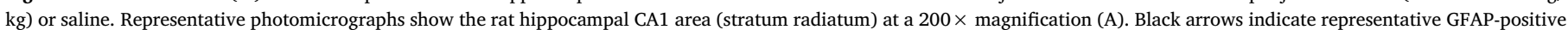

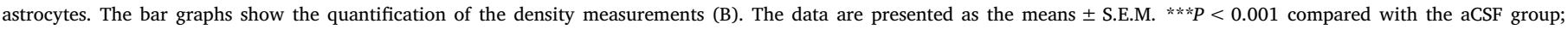
\#\#\#P $<0.001$ compared with the STZ group. One-way ANOVA followed by Bonferroni's multiple comparison test.

\subsection{Effects of muscimol and baclofen on GFAP expression}

Figs. 4 and 5 illustrate the effects of muscimol on GFAP expression in the cortex and hippocampus, respectively, of control or STZ-treated rats. Significant differences were observed between groups in the density of GFAP staining in the cortex $\left(\mathrm{F}_{5,24}=75.75, P<0.001\right.$, Fig. 4B), as well as in hippocampus $\left(\mathrm{F}_{5,24}=60.21, P<0.001\right.$, Fig. $\left.5 \mathrm{~B}\right)$. STZ induced an almost 3 -fold increase in the density of GFAP staining in the 

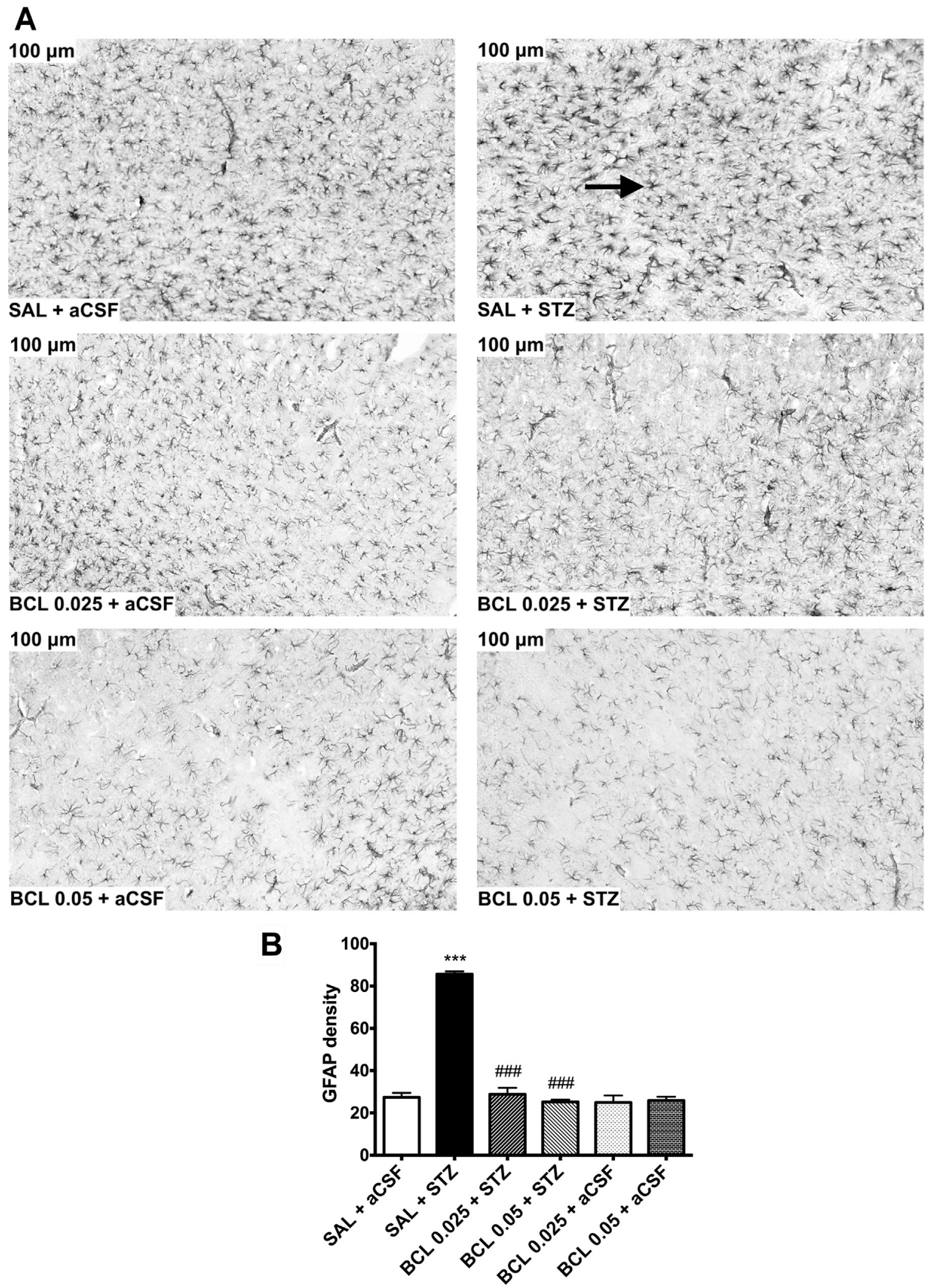

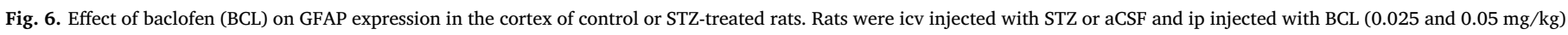

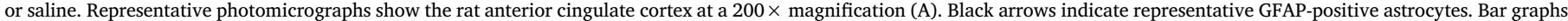

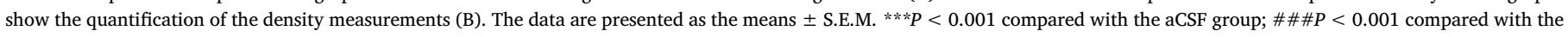
STZ group. One-way ANOVA followed by Bonferroni's multiple comparison test. 

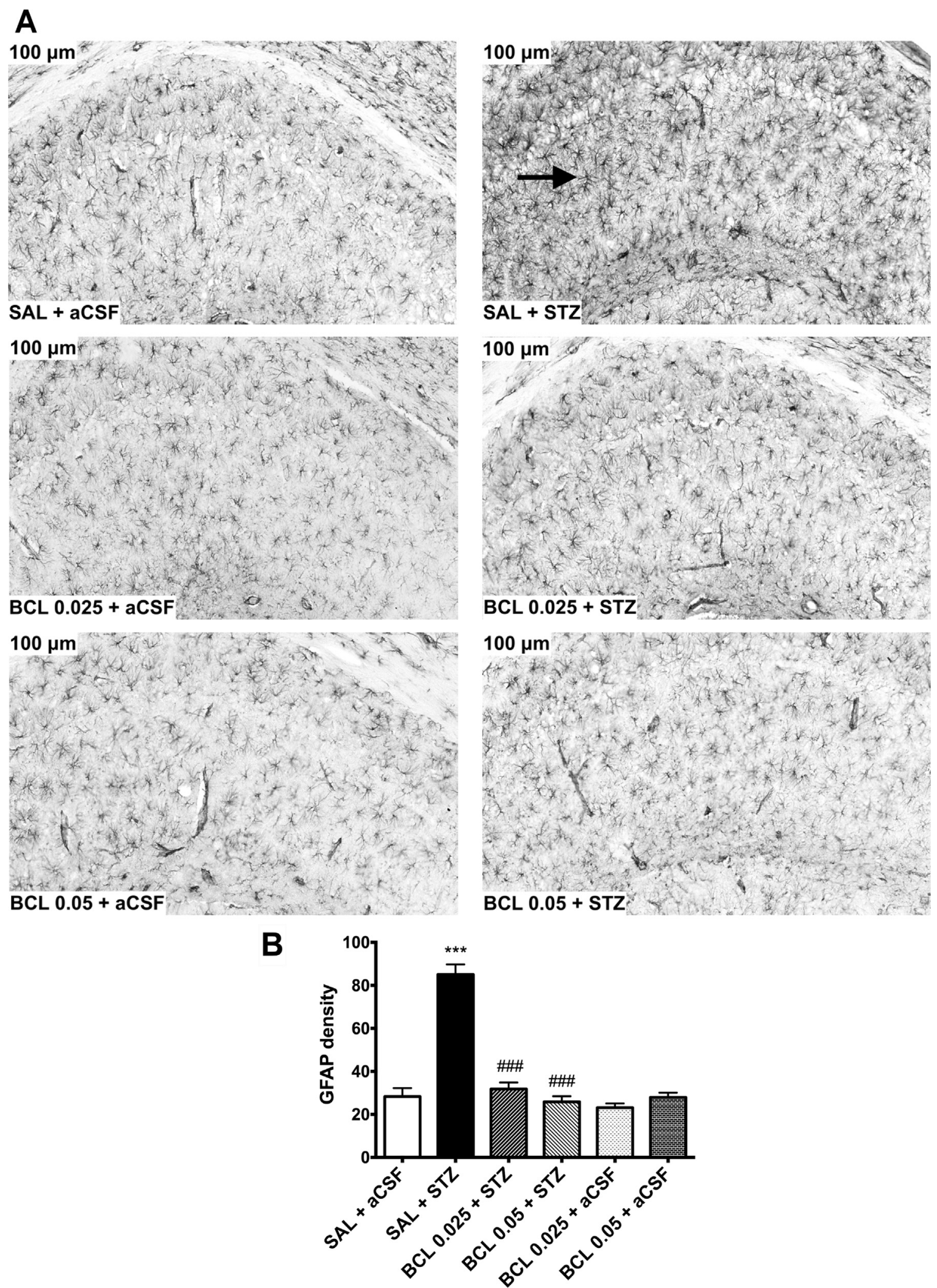

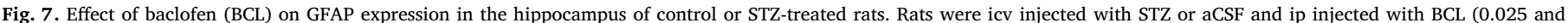

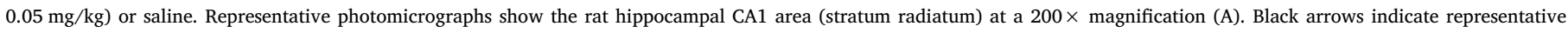

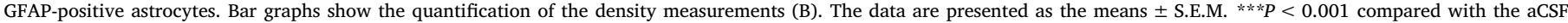
group; \#\#\#P $<0.001$ compared with the STZ group. One-way ANOVA followed by Bonferroni's multiple comparison test. 

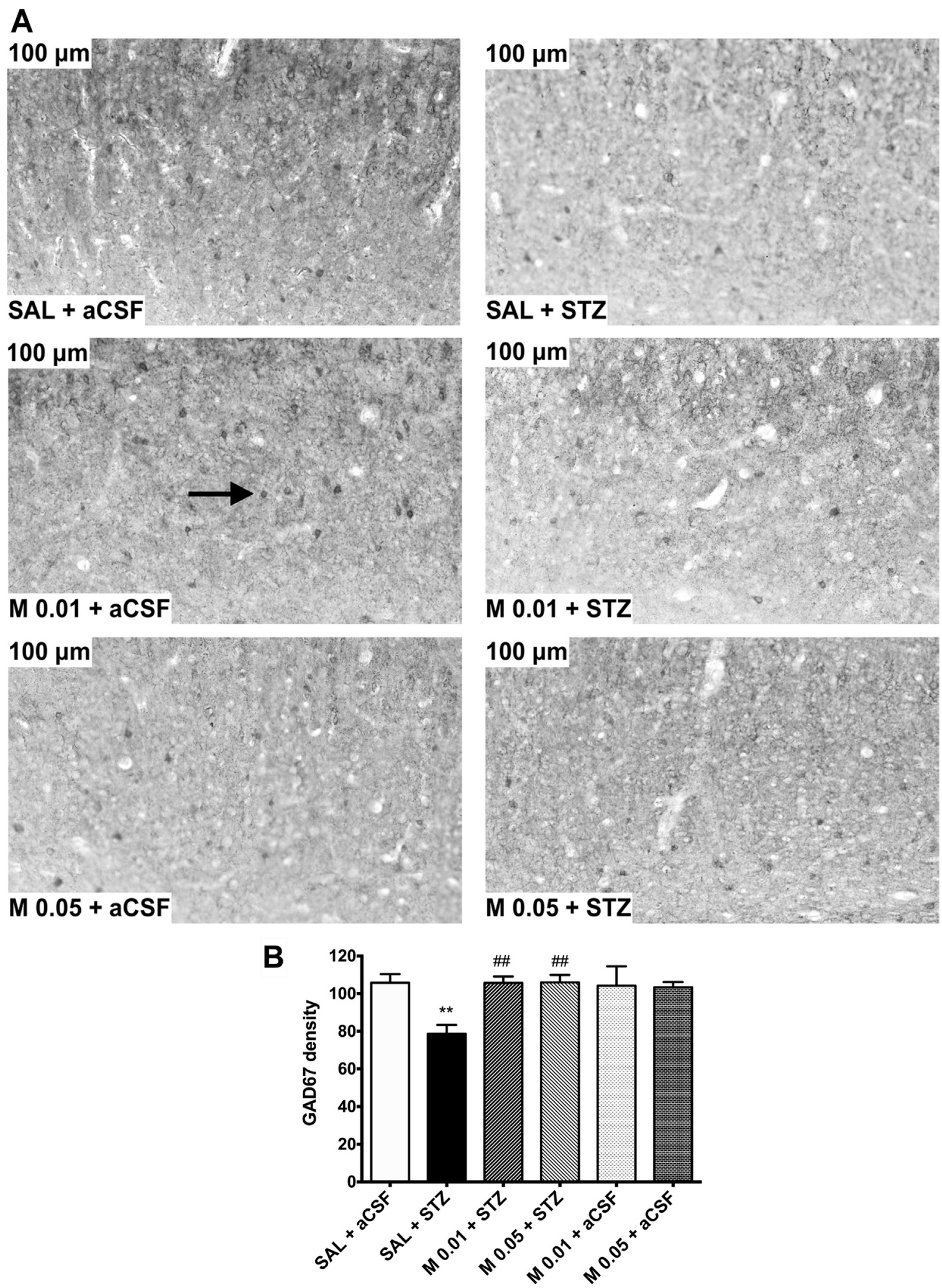

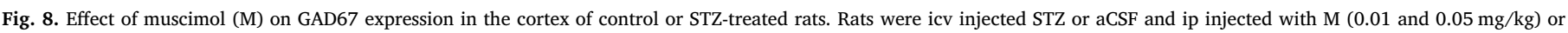

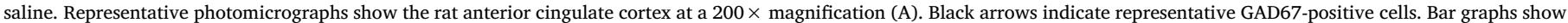

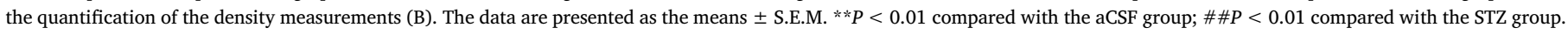
One-way ANOVA followed by Bonferroni's multiple comparison test.

cortex $(P<0.0001)$ and hippocampus $(P<0.001)$ compared to the controls.

Treatments with 0.01 and $0.05 \mathrm{mg} / \mathrm{kg}$ muscimol reversed the STZinduced increases in the density of cortical and hippocampal GFAP staining and restored its values to the levels observed in both structures of the control group $(P<0.001)$.

The effects of baclofen on cortical and hippocampal GFAP expression in control or STZ-treated rats are shown in Figs. 6 and 7, 

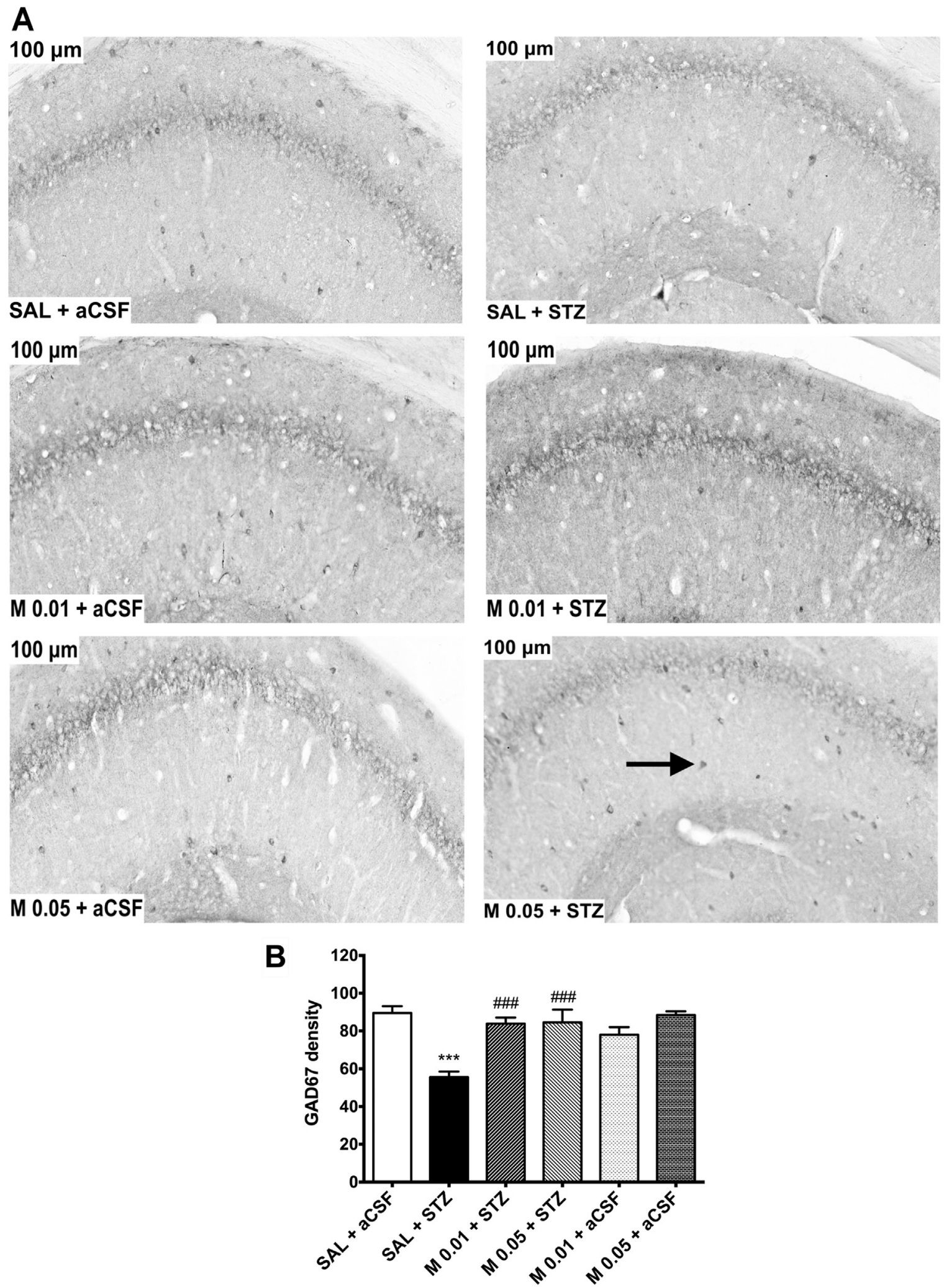

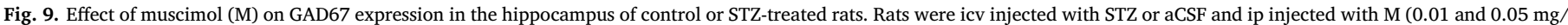

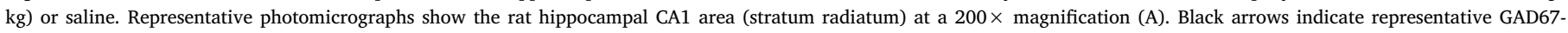

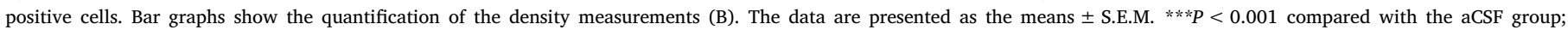
\#\#\#P $<0.001$ compared with the STZ group. One-way ANOVA followed by Bonferroni's multiple comparison test.

respectively. Significant differences were observed between groups in the density of GFAP staining in the cortex $\left(\mathrm{F}_{5,24}=116.30, P<0.001\right.$, Fig. 6B) and, similarly, in the hippocampus $\left(F_{5,24}=53.89, P<0.001\right.$, Fig. 7B). A 3-fold increase in cortical and hippocampal GFAP staining was induced by STZ $(P<0.001)$ and was reversed by both 0.025 and $0.05 \mathrm{mg} / \mathrm{kg}$ baclofen $(P<0.001)$.

In controls, neither the muscimol nor baclofen treatments produced changes in the cortical and hippocampal GFAP staining compared to 

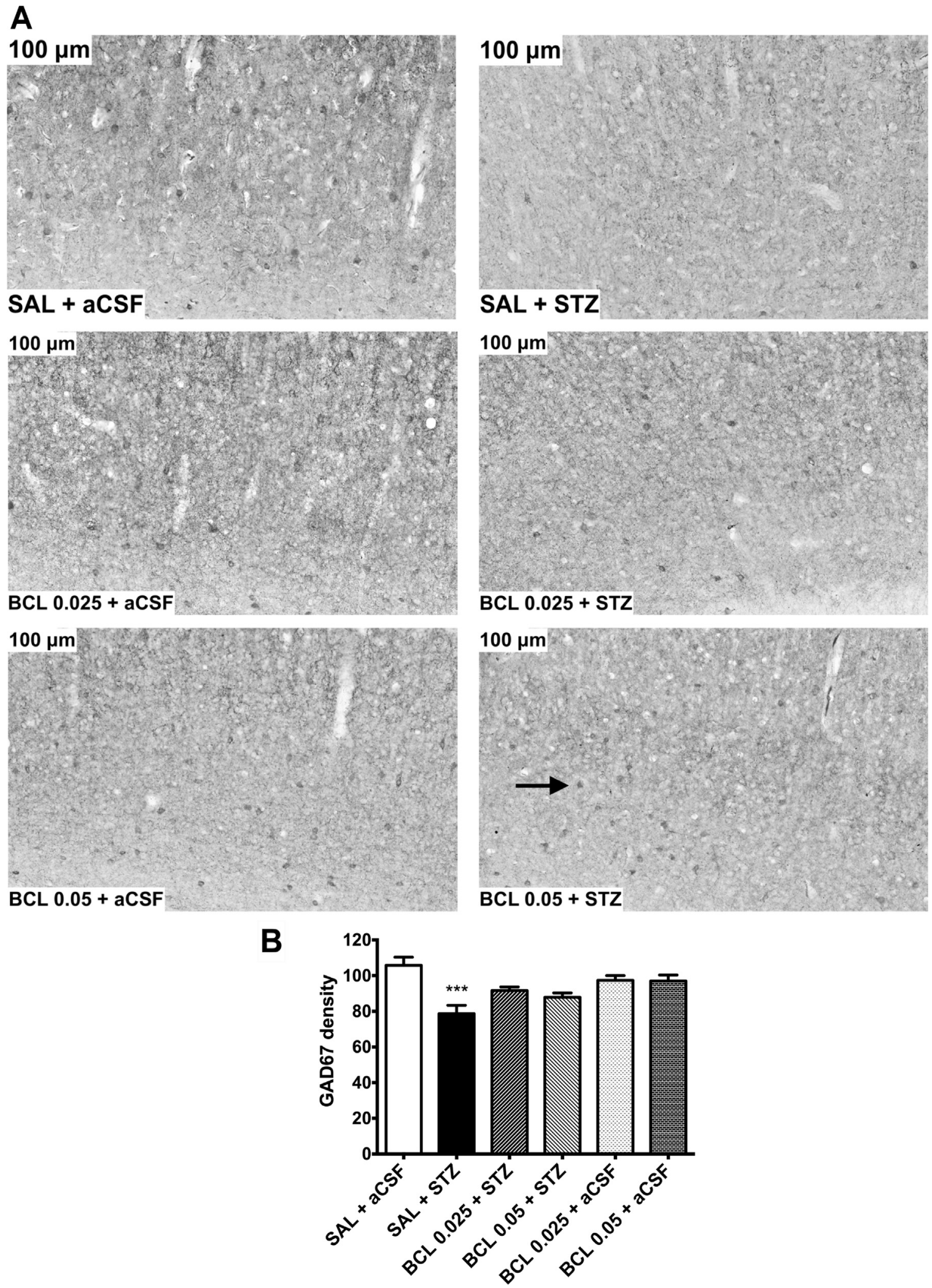

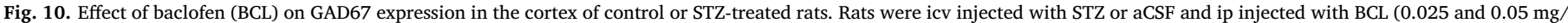

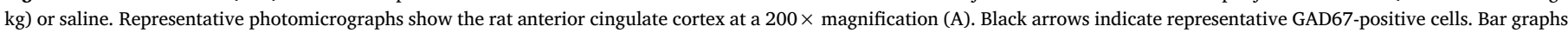

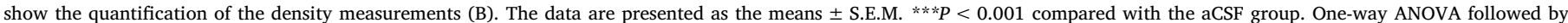
Bonferroni's multiple comparison test. 

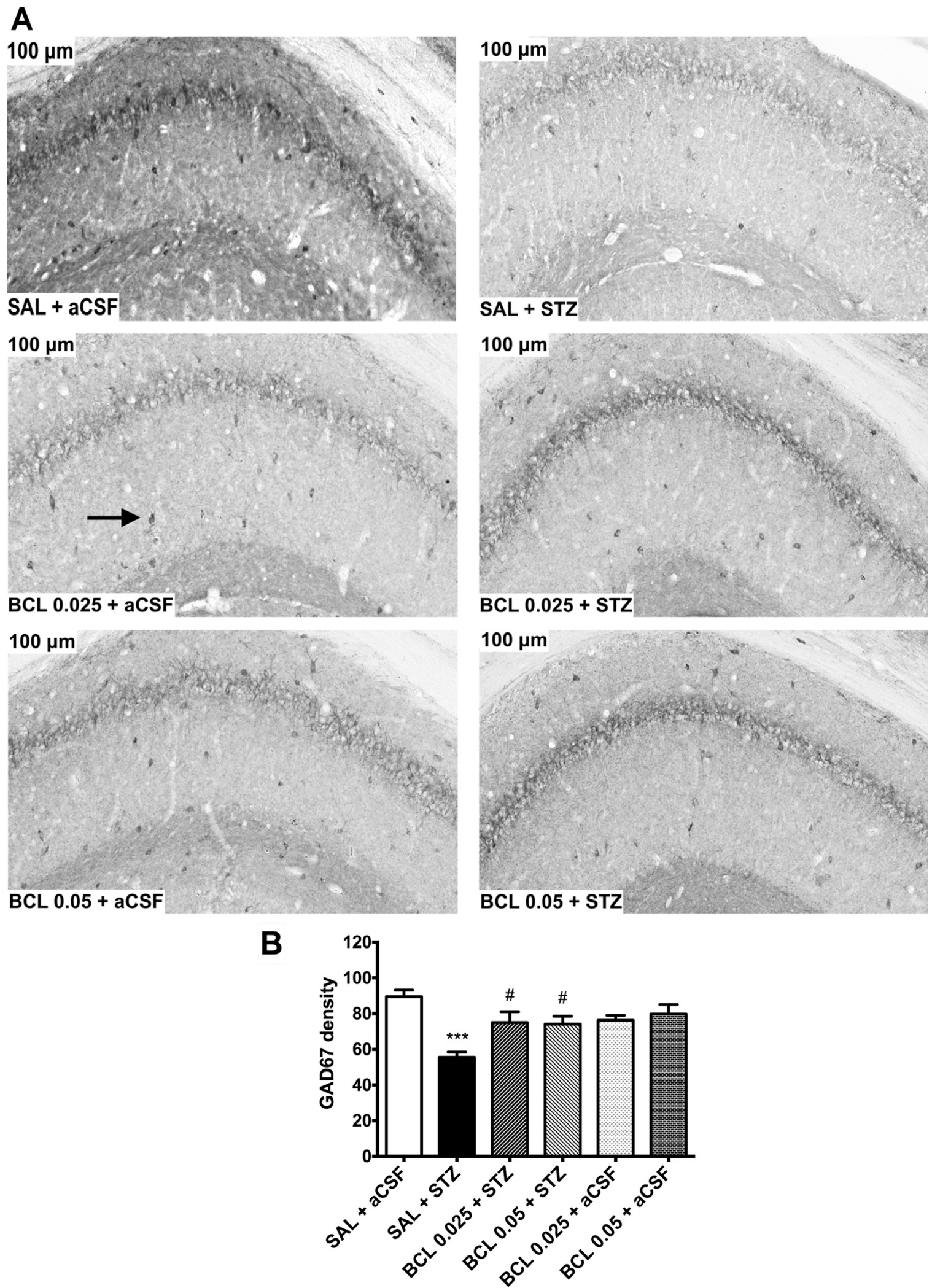

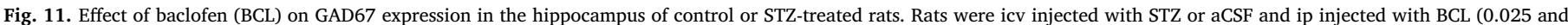

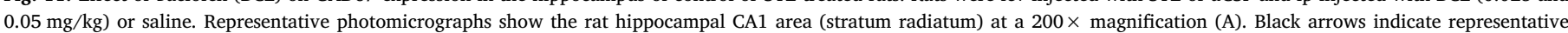

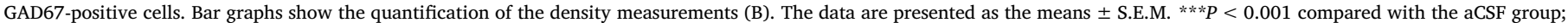
$\# P<0.05$ compared with the STZ group. One-way ANOVA followed by Bonferroni's multiple comparison test. 

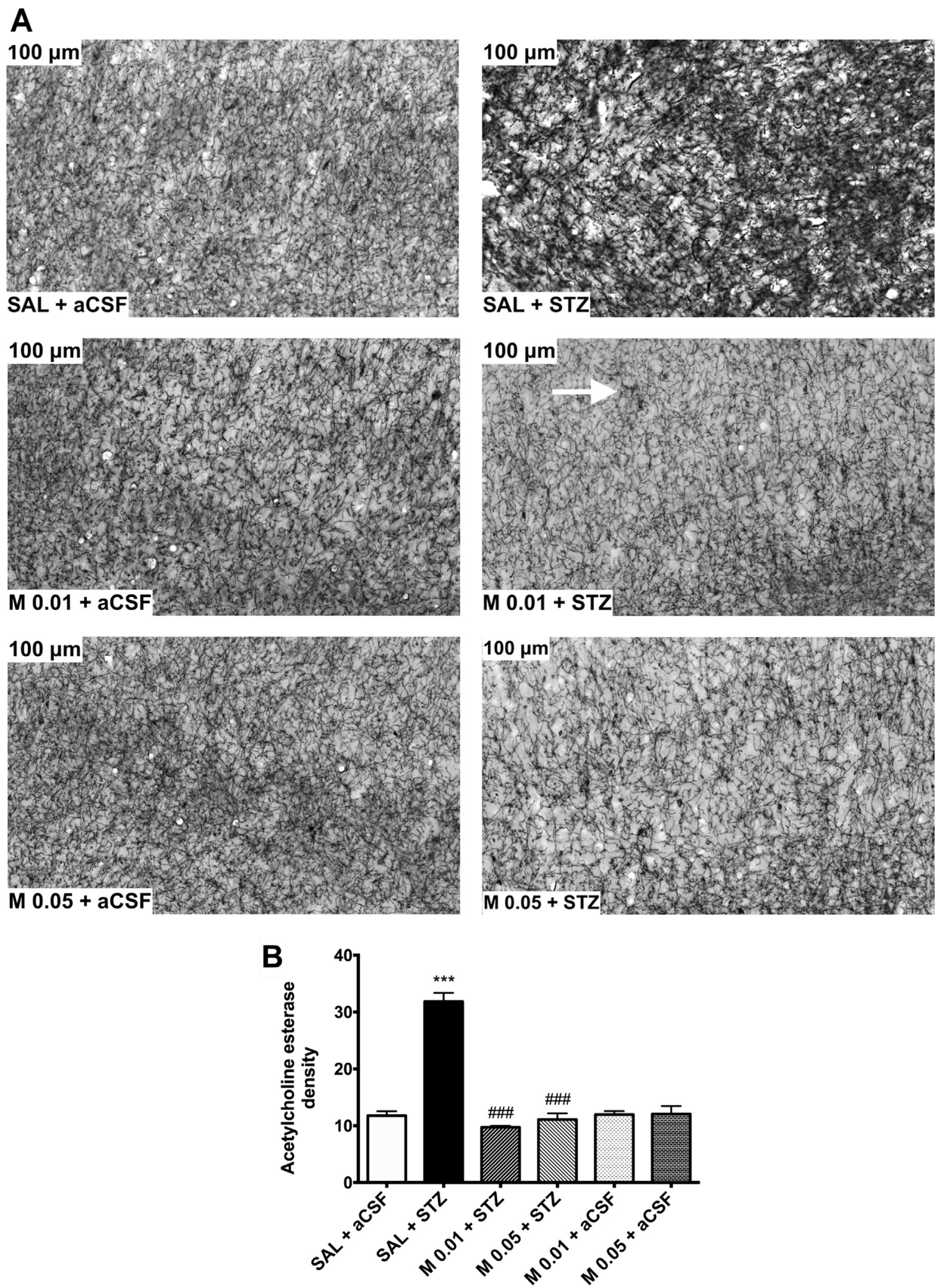

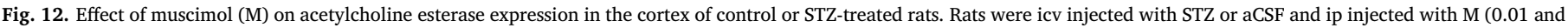

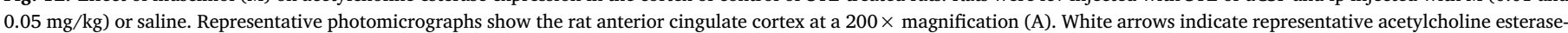

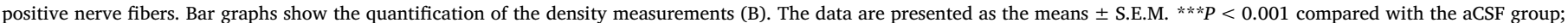
\#\#\#P $<0.001$ compared with the STZ group. One-way ANOVA followed by Bonferroni's multiple comparison test. 

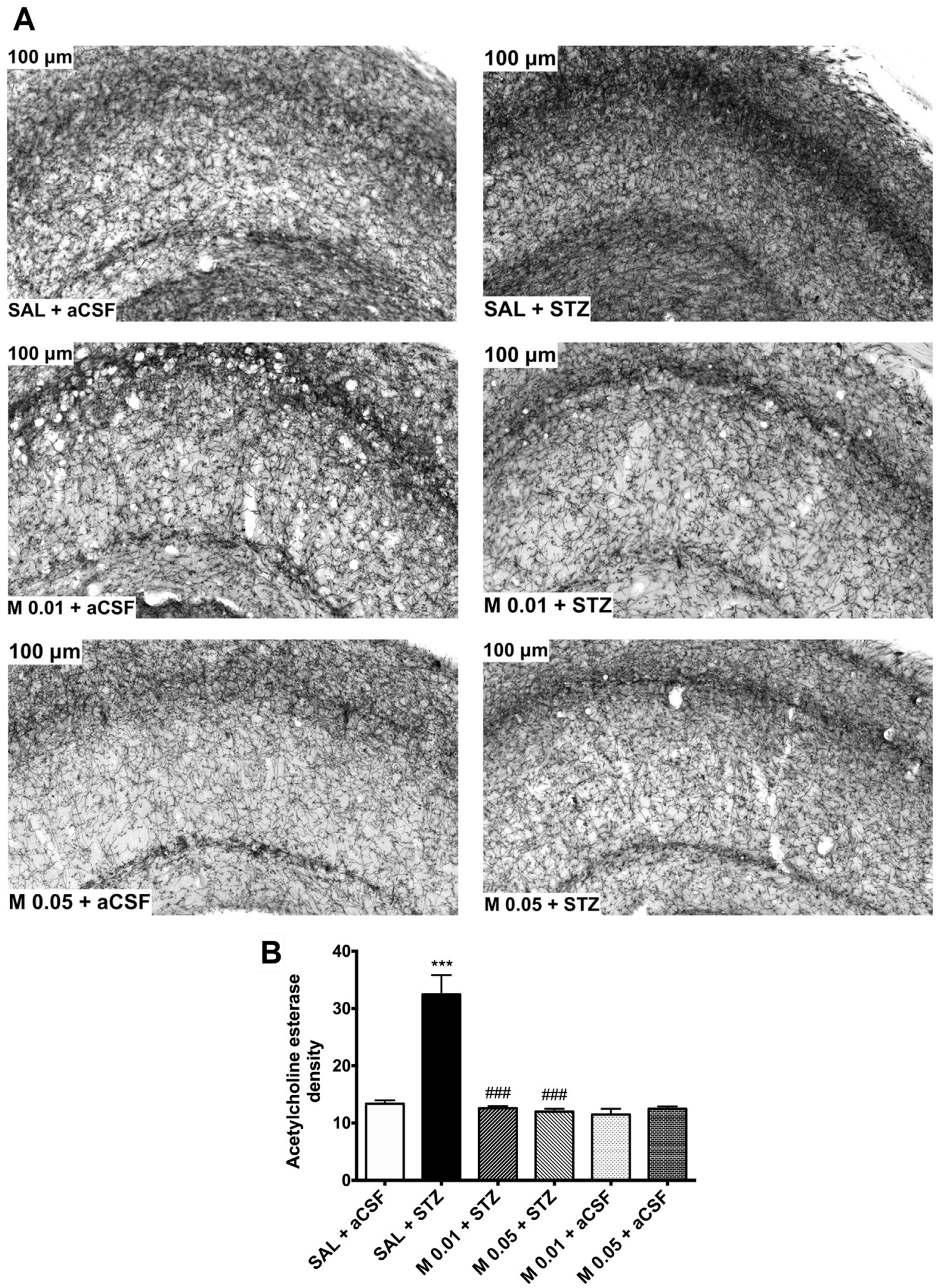

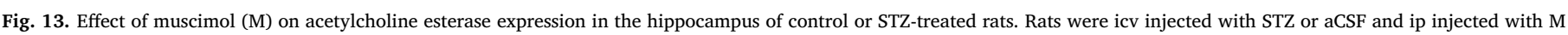

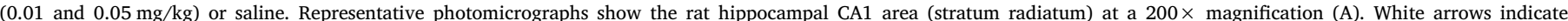

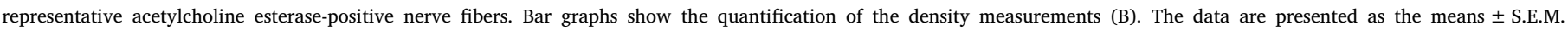
$* * * P<0.001$ compared with the aCSF group; \#\#\#P<0.001 compared with the STZ group. One-way ANOVA followed by Bonferroni's multiple comparison test. 


\section{A}
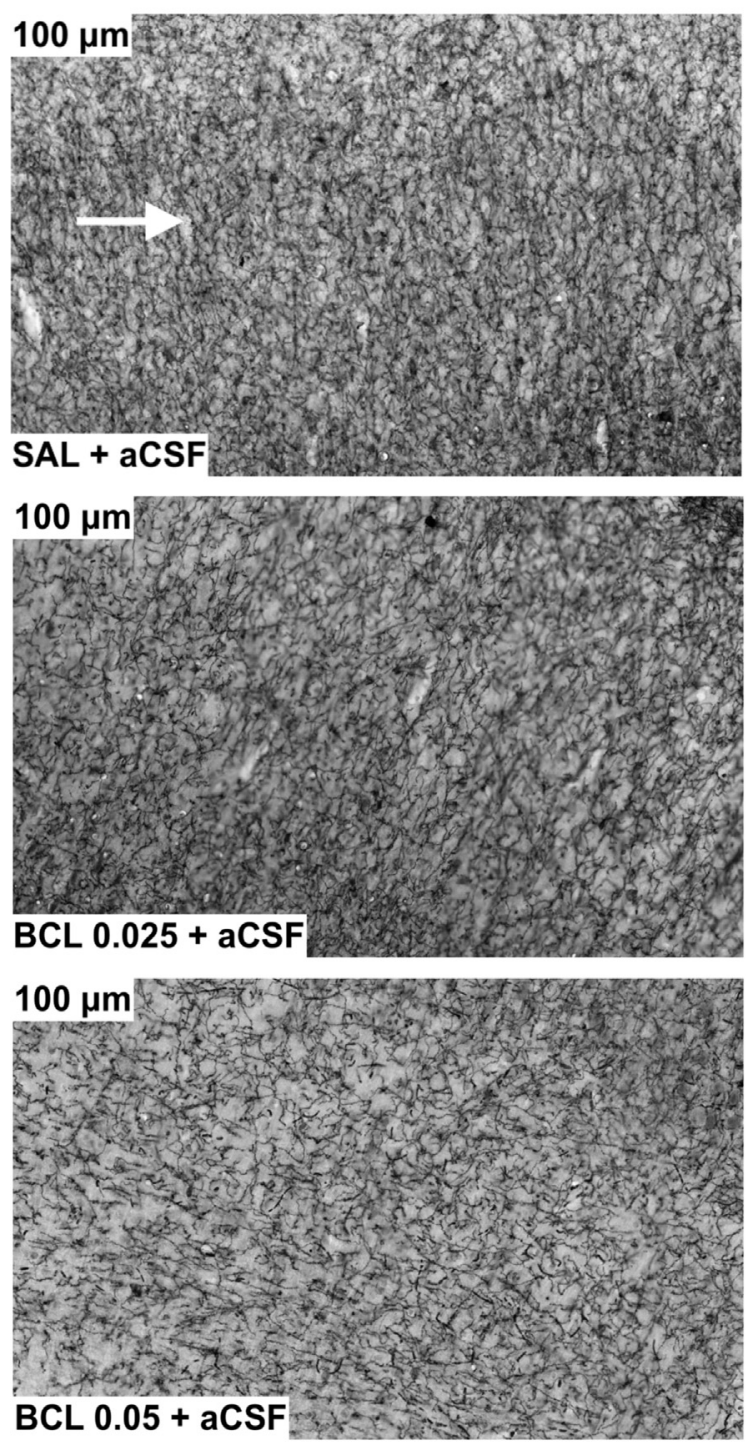
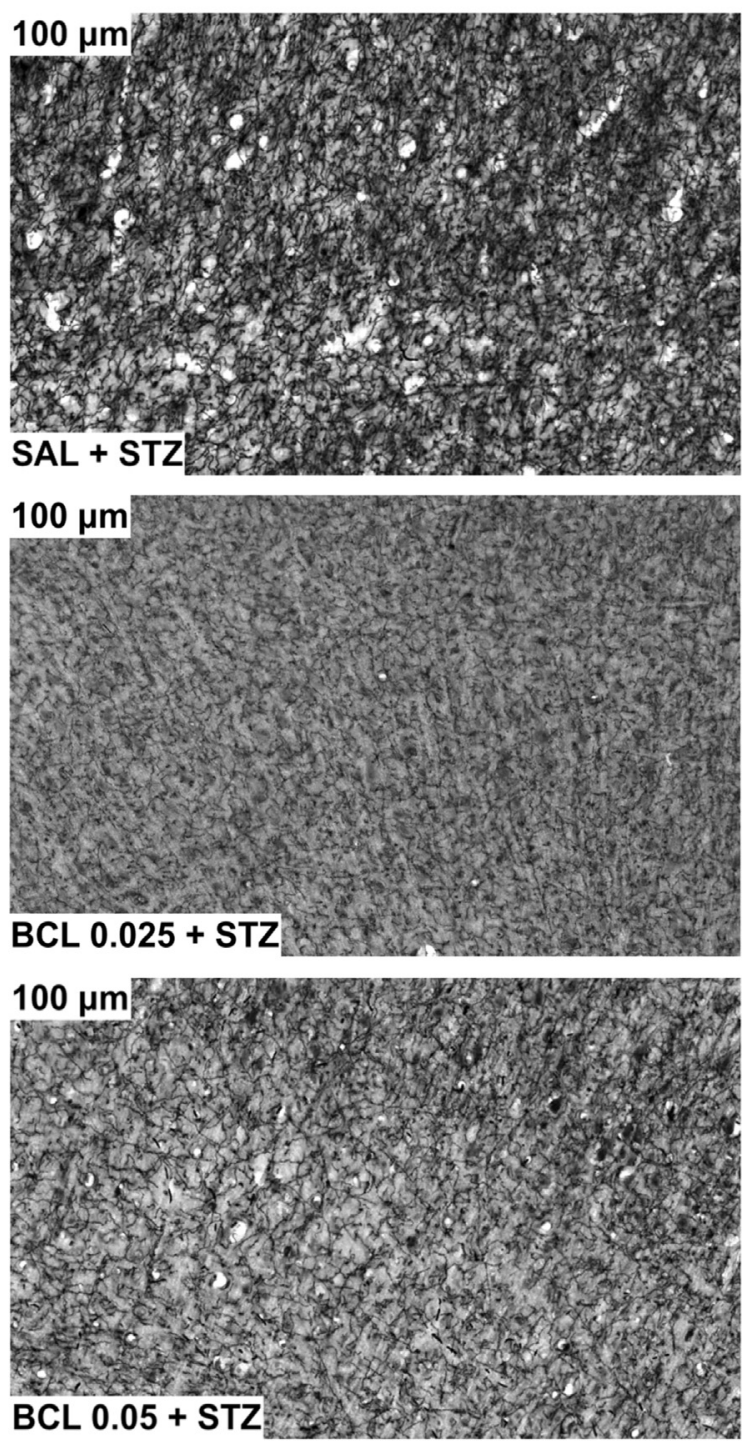

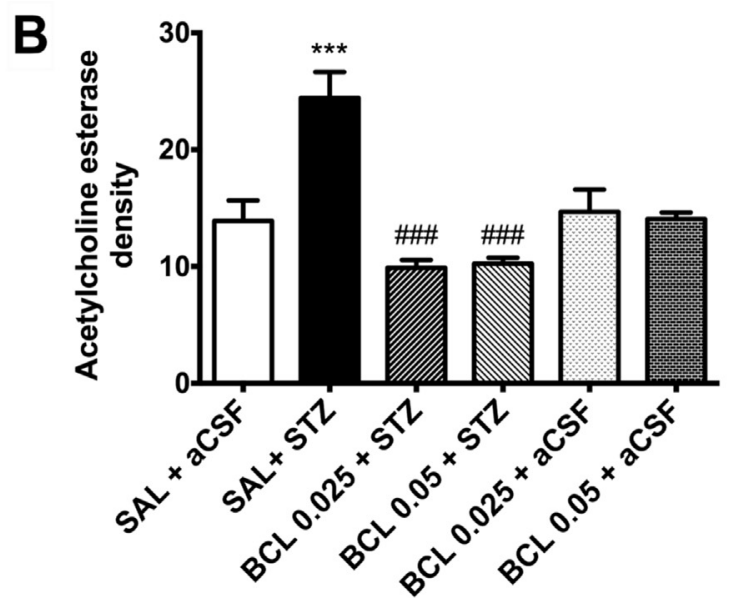

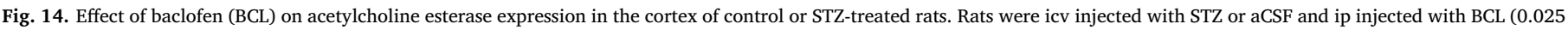

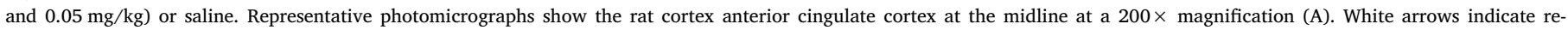

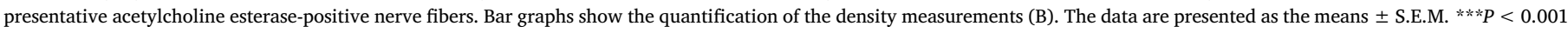
compared with the aCSF group; \#\#\#P $<0.001$ compared with the STZ group. One-way ANOVA followed by Bonferroni's multiple comparison test. 

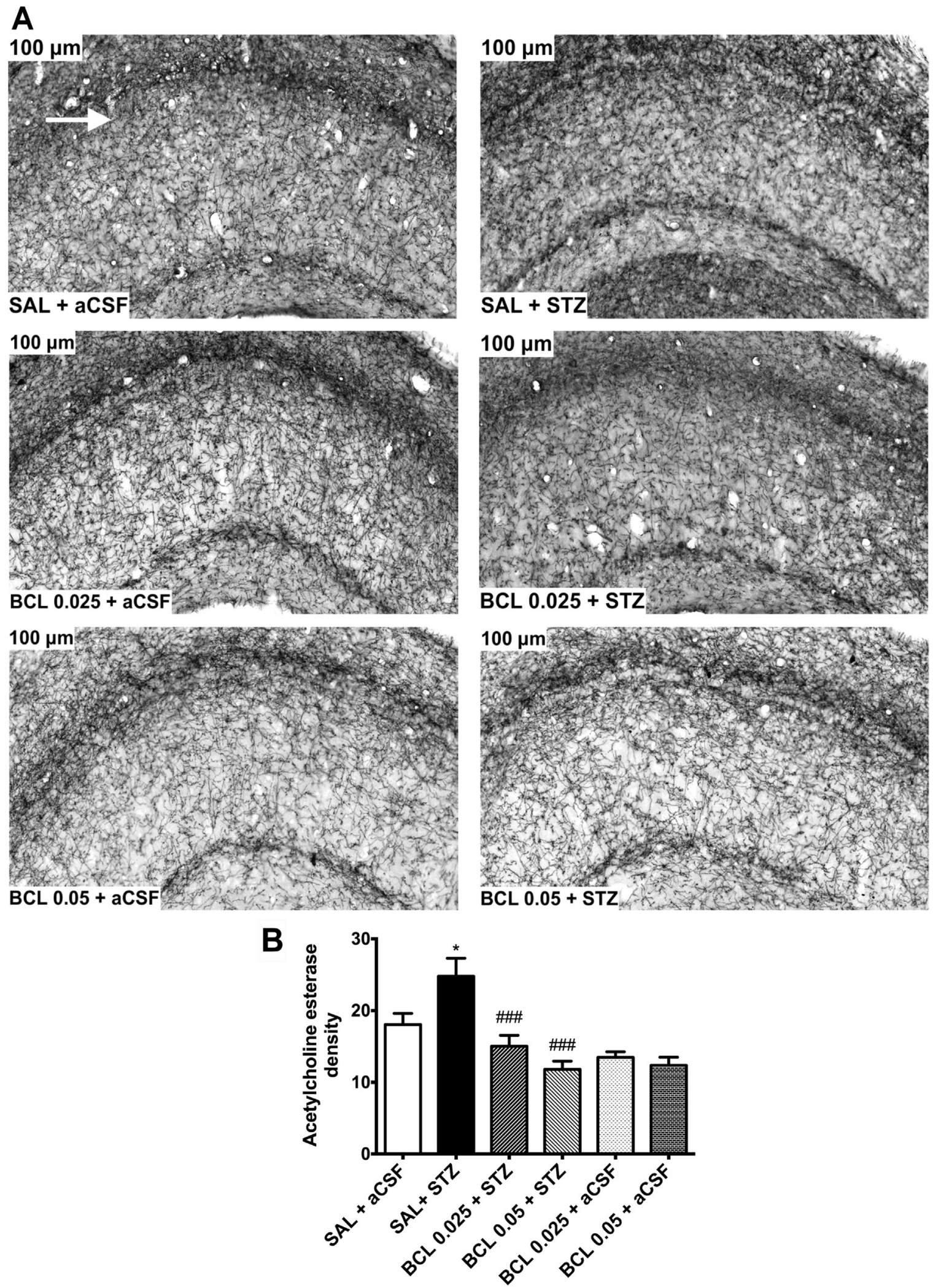

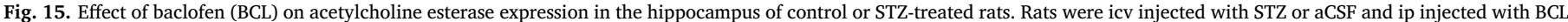

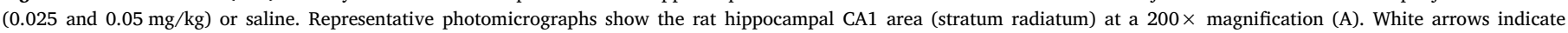

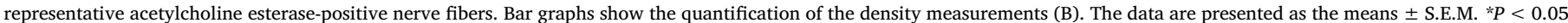
compared with the aCSF group; \#\#\#P $<0.001$ compared with the STZ group. One-way ANOVA followed by Bonferroni's multiple comparison test. 
that of the control group.

\subsection{Effects of muscimol and baclofen on GAD67 expression}

The effects of muscimol on GAD67 expression in the cortex and hippocampus of control or STZ-treated rats are depicted in Figs. 8 and 9 , respectively. Significant differences were observed between groups in cortical $\left(\mathrm{F}_{5,30}=3.80, P=0.009\right.$, Fig. $\left.8 \mathrm{~B}\right)$ and hippocampal $\left(\mathrm{F}_{5,30}=\right.$ 9.77, $P<0.001$, Fig. 9B) density of GAD67 staining.

The STZ injection produced a decrease (about $25 \%$ ) in the density of GAD67 staining in the cortex $(P<0.01)$ and approximately $40 \%$ in the hippocampus $(P<0.001)$ compared to controls. At both tested doses, muscimol reversed the STZ-induced decrease in GAD67 staining in the cortex $(P<0.01)$ and hippocampus $(P<0.001)$.

Figs. 10 and 11 illustrate the effects of baclofen on the density of cortical and hippocampal GAD67 staining in control or STZ-treated rats, respectively. Density of GAD67 staining was significantly different between groups in the cortex $\left(F_{5,30}=7.27, P<0.001\right.$, Fig. 10B $)$ and hippocampus $\left(\mathrm{F}_{5,30}=6.40, P<0.001\right.$, Fig. 11B). STZ induced a decrease in GAD67 density in the cortex $(P<0.001)$ and hippocampus $(P<0.001)$. At both tested doses, baclofen normalized the density of GAD67 staining in the hippocampus $(P<0.05)$, but not in the cortex. Treatment of animals with either muscimol or baclofen per se did not produce significant changes in the density of cortical and hippocampal GAD67 staining in comparison to the control group.

\subsection{Effects of muscimol and baclofen on acetycholine esterase expression in the rat brain}

The effects of muscimol on the density of cortical and hippocampal acetycholine esterase staining in control or STZ-treated rats are depicted in Figs. 12 and 13, respectively. Significant differences in cortical $\left(\mathrm{F}_{5,24}=64.81, P<0.001\right)$ and hippocampal $\left(\mathrm{F}_{5,22}=27.79\right.$, $P<0.001$ ) density of acetycholine esterase staining between groups were observed. Compared to controls, a 3-fold increase in the density of acetycholine esterase staining was observed in the cortex $(P<0.001)$ and hippocampus $(P<0.001)$ of STZ-treated animals. At both tested doses, muscimol reversed the effects of STZ in the cortex $(P<0.001)$ and hippocampus $(P<0.001)$.

Figs. 14 and 15 show the effects of baclofen on the density of acetycholine esterase staining in the cortex and hippocampus of control or STZ-treated rats, respectively. Cortical $\left(\mathrm{F}_{5,42}=9.57, P<0.001\right.$, Fig. 14B) and hippocampal $\left(\mathrm{F}_{5,67}=9.16, P<0.001\right.$, Fig. 15B $)$ density of acetycholine esterase staining was significantly different between groups. The STZ injection resulted in an almost 2 -fold increase in the density of acetycholine esterase staining in the cortex $(P<0.001)$ and hippocampus $(P<0.05)$ compared to controls. At both tested doses, baclofen attenuated the STZ-induced effects by normalizing the density of cortical and hippocampal acetycholine esterase staining $(P<0.001)$.

No significant changes in the density of acetycholine esterase staining were observed in control rats treated with either muscimol or baclofen per se when compared to the control group.

\section{Discussion}

The role of GABA in memory formation was postulated in the late 1990s (Kalueff and Nutt, 1997). More recent data have highlighted the importance of the GABAergic system for compensating the synaptic dysfunction observed in patients with AD (Nava-Mesa et al., 2014) and regulating neuroinflammatory processes (Crowley et al., 2016). Therefore, an approach that halts neurodegenerative pathologies in the early stages of $\mathrm{AD}$ by focusing on the GABAergic system and regulating the processes involved in neuroinflammation might be a key therapeutic strategy (Calsolaro and Edison, 2016). The distorted balance between the excitatory glutamate and inhibitory GABA systems is also an important therapeutic target for the prevention of neurodegeneration (Chumakov et al., 2015). However, we have not found data on GABA receptor agonists used in $\mathrm{AD}$ animal models in vivo. The only reports of them were examined in in vitro $\mathrm{AD}$ models. Exposure of hippocampal and cortical neurons to the GABA-A receptor agonist muscimol at a $1 \mu \mathrm{M}$ concentration inhibited $\mathrm{A} \beta$-induced neuronal death in rat hippocampal and cortical neurons (Paula-Lima et al., 2005) and blocked the Aß(25-35)-induced elevation of cytosolic $\mathrm{Ca}^{2+}$ concentrations, glutamate release and the generation of reactive oxygen species in cultured rat cortical neurons (Lee et al., 2005). In another model - glial cell lines - muscimol reduced the lipopolysaccharide (LPS)-induced release of interleukin-6 (IL-6) and tumor necrosis factor$\alpha$ (TNF- $\alpha$ ), as well as elevation of the p65 subunit of nuclear factor- $\mathrm{kB}$ (NF-kB-p65) levels (Kim et al., 2012).

Although the data on the efficacy of GABA receptor agonists in animal models of $\mathrm{AD}$ are not available, there are several reports showing memory impairment caused by muscimol at $1 \mathrm{mg} / \mathrm{kg}$ and higher doses (Castellano and McGaugh, 1990), and baclofen at 10 and $30 \mathrm{mg} / \mathrm{kg}$ (Castellano et al., 1989) in different memory tests in rodents. Interestingly, at doses $0.5,1.5$ and $2 \mathrm{mg} / \mathrm{kg}$ baclofen had no effect on fear memory and spatial learning/memory, whereas at a lower dose $0.125 \mathrm{mg} / \mathrm{kg}$ it improved memory function in healthy rats in the radial arm maze (Levin et al., 2004).

Our data examined for the first time the GABA receptor agonist action in AD model obtained by icv STZ injection that represents the early stage of $\mathrm{AD}$, manifesting as neuroinflammation, cognitive deficits and neurodegeneration in 1-4 weeks and before the toxic effects of $A ß$ and tau (Krstic and Knuesel, 2012; Nazem et al., 2015). The present study showed anti-inflammatory and memory-protecting activities of subchronically administered very low doses of GABA-A and GABA-B receptor agonists. In this study, both muscimol and baclofen at dose $0.05 \mathrm{mg} / \mathrm{kg}$ showed significantly shorter escape latency compared with the STZ group already on training day 1 , whereas lower doses (muscimol $0.01 \mathrm{mg} / \mathrm{kg}$ and baclofen $0.025 \mathrm{mg} / \mathrm{kg}$ ) protected against the STZ-induced spatial learning impairments on training days 2-4. However, both agonists in both doses demonstrated significant reversal of the decrease in platform crossings and time spent in target quadrant caused by STZ. These data indicate memory-enhancing effects of very low doses of GABA-A and GABA-B receptor agonists.

Both GABA receptor agonists also conferred protection against STZinduced hippocampal and cortical astrogliosis by reducing an almost 3fold STZ-induced increase in GFAP expression to control levels. Similar results on the concomitant memory improvement and anti-inflammatory actions of the GABA receptor agonist muscimol were observed in a rat exhaustion model: at $0.1 \mathrm{mg} / \mathrm{kg}$ it improved synaptic plasticity and spatial memory and reduced astrogliosis and diminished apoptosis in the hippocampus (Ding et al., 2015). Recently, a very low dose $(0.01 \mathrm{mg} / \mathrm{kg})$ of baclofen was shown to promote cell survival in a mouse model of Huntington's disease by exhibiting an improvement in behavior (rotarod task) and an enhanced activity of the ubiquitin-proteasome system (Kim and Seo, 2014). The anti-inflammatory action of baclofen low doses $(0.1$ and $1 \mathrm{mg} / \mathrm{kg})$ was also shown in a mouse model of allergic dermatitis (Duthey et al., 2010). At 10, 30 and $100 \mu \mathrm{M}$ concentrations, baclofen reduced inflammation in vitro by attenuating cytokine production in human immune cells isolated from patients with multiple sclerosis (Crowley et al., 2015). Incubation of activated microglial cells from Wistar rats with $10 \mu \mathrm{M}, 100 \mu \mathrm{M}$ and $1 \mathrm{mM}$ baclofen attenuated the LPS-induced increase in IL- 6 and IL-12p40 release in a dose-dependent manner (Kuhn et al., 2004). Thus, our data on the antiinflammatory action of GABA receptor agonists are consistent with these findings.

According to the present study, muscimol and baclofen substantially reduced the STZ-induced overexpression (2-fold) of acetycholine esterase in nerve fibers in the cortex and hippocampus, indicating a mechanism which promotes acetylcholine accumulation. Acetylcholine plays an essential role in enhancing memory (Micheau and Marighetto, 2011), therefore, the inhibition of its metabolism is still considered a 
treatment strategy to delay the development of AD (Haussmann and Donix, 2016).

In the present study, the STZ treatment decreased cortical GAD67 expression by approximately $25 \%$ and hippocampal GAD67 expression by approximately $40 \%$. Muscimol and baclofen normalized this reduction to control values, indicating that both agonists normalized GABA synthesis, which is essential to prevent spatial learning/memory deficits. In this context, it is important that GABA has been shown to covesiculate with key neurotransmitters, such as acetylcholine and dopamine (Tritsch et al., 2016), and through their co-release, GABA might regulate the neurotransmitter cycle in both the developing and diseased central nervous system (Dulcis et al., 2013; Hnasko and Edwards, 2012). Although GABA production in the brains of $A D$ patients is considered stable (Luchetti et al., 2011; Rissman et al., 2007; Warren et al., 2013), post-mortem studies of different areas of the brains from patients with $\mathrm{AD}$ showed substantial (20-47\%) reductions in the GABA concentrations and GAD activity (Lanctôt et al., 2004).

Based on obtained data in STZ-induced AD model, one may suggest that similar memory-enhancing effects of GABA-A and GABA-B receptor agonists at very low doses involve, to a great extent, protection against neuroinflammation and increased acetylcholine degradation.

The obtained data raise the following questions: 1) what is the target of the anti-inflammatory and memory-normalizing effects of very low doses of GABA receptor agonists? 2) Is direct binding to an appropriate GABA receptor subtype required for these effects? Currently, we cannot easily address these questions due to the flexibility and diversity of the GABA circuit architecture and co-transmission of GABA signaling (Tritsch et al., 2016). For example, different ultrastructures of GABA synapses are currently recognized, such as type 1 (primarily identified in the synaptic cleft and considered excitatory) and type 2 (generally thought to be inhibitory), which may provide distinct pharmacological sensitivity, ionic selectivity and kinetic properties (Owens and Kriegstein, 2002). Second, 18 subunits of GABA-A receptor have been identified to interact in different combinations and exert distinct effects (Enna and McCarson, 2013). Thus, compared to GABA-A receptors containing $\gamma$-subunits that are mainly localized post-synaptically, $\delta$-subunit-containing GABA-A receptors are predominantly localized extra-synaptically. Interestingly, micromolar concentrations of the GABA and GABA-A receptor agonist muscimol displayed 8-22-fold higher potency at high-affinity extra-synaptic receptors than at synaptic receptors (Ahring et al., 2016). This complexity might also be attributed to the GABA-B receptor and its subunits. Thus, GABA-B $(1 \mathrm{a}, 2)$ receptors are located pre-synaptically, whereas GABA-B $(1 \mathrm{~b}, 2)$ receptors are predominantly expressed post-synaptically (Gassmann and Bettler, 2012; Marshall et al., 1999; O’Leary et al., 2014).

Based on the above-mentioned complexity of the GABAergic system, we suggest that the effects of muscimol and baclofen observed in the present study were mediated by either their binding to non-specific sites of GABA receptors or the activation of allosteric regulatory mechanisms, thereby leading to the maintenance of cell integrity and normal functioning. Stimulatory activities might also involve $\mathrm{Ca}^{2+}$ influx, similar to subthreshold GABA-induced depolarization (Tritsch et al., 2016).

In summary, we provided the first evidence that very low microgram doses of the GABA-A and GABA-B receptor agonists muscimol and baclofen acted in a similar manner in a rat model of STZ-induced AD by improving learning/memory and normalizing protein expression in the brain, particularly proteins related to neuroinflammation and the cholinergic system. One may suggest the usefulness of neuroprotective action of low doses of muscimol and baclofen in the early stages of AD. However, questions concerning non-specific regulatory cell targets remain to be answered.

\section{Acknowledgments}

This work was co-funded by a grant (No. NFI/R/2014/023) from the EEA and Norwegian Financial Mechanism Project. The authors would like to thank Inga Kadish, Thomas van Groen and Pēteris Alberts for providing valuable comments on the manuscript.

\section{Conflict of interest}

The authors have no conflicts of interest to declare.

\section{References}

Ahring, P.K., Bang, L.H., Jensen, M.L., Strøbæk, D., Hartiadi, L.Y., Chebib, M., Absalom, N., 2016. A pharmacological assessment of agonists and modulators at $\alpha 4 \beta 2 \gamma 2$ and $\alpha 4 \beta 2 \delta$ GABAA receptors: the challenge in comparing apples with oranges. Pharmacol. Res. 111, 563-576. http://dx.doi.org/10.1016/j.phrs.2016.05.014.

Buckwalter, M.S., Wyss-Coray, T., 2004. Modelling neuroinflammatory phenotypes in vivo. J. Neuroinflamm. 1, 10. http://dx.doi.org/10.1186/1742-2094-1-10.

Butterfield, D.A., Pocernich, C.B., 2003. The glutamatergic system and Alzheimer's disease: therapeutic implications. CNS Drugs 17, 641-652. http://dx.doi.org/10.2165/ 00023210-200317090-00004.

Calabrese, V., Cornelius, C., Dinkova-Kostova, A.T., Calabrese, E.J., Mattson, M.P., 2010. Cellular stress responses, the hormesis paradigm, and vitagenes: novel targets for therapeutic intervention in neurodegenerative disorders. Antioxid. Redox Signal. 13, 1763-1811. http://dx.doi.org/10.1089/ars.2009.3074.

Calsolaro, V., Edison, P., 2016. Neuroinflammation in Alzheimer's disease: current evidence and future directions. Alzheimers Dement. 12, 719-732. http://dx.doi.org/10. 1016/j.jalz.2016.02.010.

Castellano, C., Brioni, J.D., Nagahara, A.H., McGaugh, J.L., 1989. Post-training systemic and intra-amygdala administration of the GABA-B agonist baclofen impairs retention. Behav. Neural Biol. 52, 170-179. http://dx.doi.org/10.1016/S0163-1047(89) 90285-9.

Castellano, C., McGaugh, J.L., 1990. Effects of post-training bicuculline and muscimol on retention: lack of state dependency. Behav. Neural Biol. 54, 156-164. http://dx.doi. org/10.1016/0163-1047(90)91352-C.

Chen, Y., Liang, Z., Blanchard, J., Dai, C.L., Sun, S., Lee, M.H., Grundke-Iqbal, I., Iqbal, K., Liu, F., Gong, C.X., 2012. A Non-transgenic mouse model (icv-STZ mouse) of Alzheimer's disease: similarities to and differences from the transgenic model (3xTgAD mouse). Mol. Neurobiol. 47, 1-15. http://dx.doi.org/10.1007/s12035-0128375-5.

Chumakov, I., Nabirotchkin, S., Cholet, N., Milet, A., Boucard, A., Toulorge, D., Pereire, Y., Graudens, E., Traore, S., Foucquier, J., Guedj, M., Vial, E., Callizot, N., Steinschneider, R., Maurice, T., Bertrand, V., Scart-Gres, C., Hajj, R., Cohen, D., 2015. Combining two repurposed drugs as a promising approach for Alzheimer's disease therapy. Sci. Rep. 5, 1-12. http://dx.doi.org/10.1038/srep07608.

Correia, S.C., Perry, G., Moreira, P.I., 2016. Mitochondrial traffic jams in Alzheimer's disease - pinpointing the roadblocks. Biochim. Biophys. Acta - Mol. Basis Dis. 1862, 1909-1917. http://dx.doi.org/10.1016/j.bbadis.2016.07.010.

Crowley, T., Cryan, J.F., Downer, E.J., O'Leary, O.F., 2016. Inhibiting neuroinflammation: the role and therapeutic potential of GABA in neuro-immune interactions. Brain Behav. Immun. 54, 260-277. http://dx.doi.org/10.1016/j.bbi.2016.02.001.

Crowley, T., Fitzpatrick, J.-M., Kuijper, T., Cryan, J.F., O’Toole, O., O'Leary, O.F., Downer, E.J., 2015. Modulation of TLR3/TLR4 inflammatory signaling by the GABAB receptor agonist baclofen in glia and immune cells: relevance to therapeutic effects in multiple sclerosis. Front. Cell. Neurosci. 9, 284. http://dx.doi.org/10.3389/fncel. 2015.00284.

Deiana, S., Platt, B., Riedel, G., 2011. The cholinergic system and spatial learning. Behav. Brain Res. 221, 389-411. http://dx.doi.org/10.1016/j.bbr.2010.11.036.

Ding, Y., Xie, L., Chang, C.Q., Chen, Z.M., Ai, H., 2015. Activation of $\gamma$-aminobutyric acid (A) receptor protects hippocampus from intense exercise-induced synapses damage and apoptosis in rats. Chin. Med. J. 128, 2330-2339. http://dx.doi.org/10.4103/ 0366-6999.163392.

Dulcis, D., Jamshidi, P., Leutgeb, S., Spitzer, N.C., 2013. Neurotransmitter switching in the adult brain regulates behavior. Science 340, 449-453. http://dx.doi.org/10. 1126/science.1234152.

Duthey, B., Hübner, A., Diehl, S., Boehncke, S., Pfeffer, J., Boehncke, W.H., 2010. Antiinflammatory effects of the GABAB receptor agonist baclofen in allergic contact dermatitis. Exp. Dermatol. 19, 661-666. http://dx.doi.org/10.1111/j.1600-0625. 2010.01076.x.

Enna, S.J., McCarson, K.E., 2013. Characterization of GABA receptors. Curr. Protoc. Pharmacol. 1, 1-26. http://dx.doi.org/10.1002/0471141755.ph0107s63.

Gassmann, M., Bettler, B., 2012. Regulation of neuronal GABAB receptor functions by subunit composition. Nat. Rev. Neurosci. 13, 380-394. http://dx.doi.org/10.1038/ nrn3249.

Haussmann, R., Donix, M., 2016. Memantin als Add-on-Medikation zur Acetylcholinesteraseinhibitor-Therapie bei Alzheimer-Demenz. Nervenarzt. http:// dx.doi.org/10.1007/s00115-016-0237-3.

Hnasko, T.S., Edwards, R.H., 2012. Neurotransmitter co-release: mechanism and physiological role. Annu. Rev. Physiol. 225-243. http://dx.doi.org/10.1146/annurevphysiol-020911-153315.Neurotransmitter.

Kadish, I., Van Groen, T., 2002. Low levels of estrogen significantly diminish axonal sprouting after entorhinal cortex lesions in the mouse. J. Neurosci. 22, 4095-4102 (doi: 20026393).

Kalueff, A., Nutt, D.J., 1997. Role of GABA in memory and anxiety. Depress. Anxiety 100-110. http://dx.doi.org/10.1002/(SICI)1520-6394(1996)4:3<100::AID-DA2 > 3 . 
0.CO;2-K

Karnovsky, J.M., Roots, L., 1964. A "direct-coloring" thiocholine method for cholinesterases. J. Histochem. Cytochem. 219-221. http://dx.doi.org/10.1177/12.3.219.

Kim, D.H., Kim, J.M., Park, S.J., Cai, M., Liu, X., Lee, S., Shin, C.Y., Ryu, J.H., 2012. GABA(A) receptor blockade enhances memory consolidation by increasing hippocampal BDNF levels. Neuropsychopharmacology 37, 422-433. http://dx.doi.org/10. 1038/npp.2011.189.

Kim, W., Seo, H., 2014. Baclofen, a GABAB receptor agonist, enhances ubiquitin-proteasome system functioning and neuronal survival in Huntington's disease model mice. Biochem. Biophys. Res. Commun. 443, 706-711. http://dx.doi.org/10.1016/j. bbrc. 2013.12.034.

Krantic, S., Isorce, N., Mechawar, N., Davoli, M.A., Vignault, E., Albuquerque, M., Chabot, J.G., Moyse, E., Chauvin, J.P., Aubert, I., McLaurin, J., Quirion, R., 2012. Hippocampal GABAergic neurons are susceptible to amyloid- $\beta$ toxicity in vitro and are decreased in number in the alzheimer's disease TgCRND8 mouse model. J. Alzheimer's Dis. 29, 293-308, http://dx doi.org/10.3233/JAD-2011-110830.

Krstic, D., Knuesel, I., 2012. Deciphering the mechanism underlying late-onset Alzheimer disease. Nat. Rev. Neurol. 9, 25-34. http://dx.doi.org/10.1038/nrneurol.2012.236.

Kuhn, S.A., Van Landeghem, F.K.H., Zacharias, R., Färber, K., Rappert, A., Pavlovic, S. Hoffmann, A., Nolte, C., Kettenmann, H., 2004. Microglia express GABAB receptors to modulate interleukin release. Mol. Cell. Neurosci. 25, 312-322. http://dx.doi.org/10. 1016/j.mcn.2003.10.023.

Lanctôt, K.L., Herrmann, N., Mazzotta, P., Khan, L.R., Ingber, N., 2004. GABAergic function in Alzheimer's disease: evidence for dysfunction and potential as a therapeutic target for the treatment of behavioural and psychological symptoms of dementia. Can. J. Psychiatry 49, 439-453. http://dx.doi.org/10.1177/ 070674370404900705.

Lee, Y.B., Ban, Y.J., Seong, Y.H., 2005. Chronic stimulation of GABAA receptor with muscimol reduces amyloid $ß$ protein (25-35)-induced neurotoxicity in cultured rat cortical cells. Neurosci. Res. 52, 347-356. http://dx.doi.org/10.1016/j.neures.2005. 04.008.

Levin, E.D., Weber, E., Icenogle, L., 2004. Baclofen interactions with nicotine in rats: effects on memory. Pharmacol. Biochem. Behav. 79, 343-348. http://dx.doi.org/10. 1016/j.pbb.2004.08.013.

Limon, A., Reyes-Ruiz, J.M., Miledi, R., 2012. Loss of functional GABAA receptors in the Alzheimer diseased brain. Proc. Natl. Acad. Sci. USA 109, 10071-10076. http://dx. doi.org/10.1073/pnas.1204606109.

Luchetti, S., Huitinga, I., Swaab, D.F., 2011. Neurosteroid and GABA-A receptor alterations in Alzheimer's disease, Parkinson's disease and multiple sclerosis. Neuroscience 191, 6-21. http://dx.doi.org/10.1016/j.neuroscience.2011.04.010.

Marshall, F.H., Jones, K.A., Kaupmann, K., Bettler, B., 1999. GABA(B) receptors - the first 7TM heterodimers. Trends Pharmacol. Sci. 20, 396-399. http://dx.doi.org/10.1016/ S0165-6147(99)01383-8.

McManus, R.M., Heneka, M.T., 2017. Role of neuroinflammation in neurodegeneration: new insights. Alzheimers Res. Ther. 9, 14. http://dx.doi.org/10.1186/s13195-0170241-2.

McNaull, B.B.A., Todd, S., McGuinness, B., Passmore, A.P., 2010. Inflammation and antiinflammatory strategies for Alzheimer's disease - a mini-review. Gerontology 56, 3-14. http://dx.doi.org/10.1159/000237873.

Mendiola-Precoma, J., Berumen, L.C., Padilla, K., Garcia-Alcocer, G., 2016. Therapies for prevention and treatment of Alzheimer's disease. Biomed. Res. Int. 2016. http://dx. doi.org/10.1155/2016/2589276.

Micheau, J., Marighetto, A., 2011. Acetylcholine and memory: a long, complex and chaotic but still living relationship. Behav. Brain Res. 221, 424-429. http://dx.doi. org/10.1016/j.bbr.2010.11.052.

Nava-Mesa, M.O., Jiménez-Díaz, L., Yajeya, J., Navarro-Lopez, J.D., 2014. GABAergic neurotransmission and new strategies of neuromodulation to compensate synaptic dysfunction in early stages of Alzheimer's disease. Front. Cell. Neurosci. 8, 167. http://dx.doi.org/10.3389/fncel.2014.00167.

Nazem, A., Sankowski, R., Bacher, M., Al-Abed, Y., 2015. Rodent models of neuroinflammation for Alzheimer's disease. J. Neuroinflamm. 12, 74. http://dx.doi.org/10. 1186/s12974-015-0291-y.

O'Leary, O.F., Felice, D., Galimberti, S., Savignac, H.M., Bravo, J.A., Crowley, T., El Yacoubi, M., Vaugeois, J.-M., Gassmann, M., Bettler, B., Dinan, T.G., Cryan, J.F., 2014. GABAB(1) receptor subunit isoforms differentially regulate stress resilience. Proc. Natl. Acad. Sci. USA 111, 15232-15237. http://dx.doi.org/10.1073/pnas. 1404090111.

Obata, K., 2013. Synaptic inhibition and ^|^gamma;-aminobutyric acid in the mammalian central nervous system. Proc. Jpn. Acad. Ser. B 89, 139-156. http://dx.doi.org/10. 2183/pjab.89.139.

Oren, I., Mann, E.O., Paulsen, O., Hájos, N., 2006. Synaptic currents in anatomically identified CA3 neurons during hippocampal gamma oscillations in vitro. J. Neurosci. 26, 9923-9934. http://dx.doi.org/10.1523/JNEUROSCI.1580-06.2006.

Owens, D.F., Kriegstein, A.R., 2002. Is there more to GABA than synaptic inhibition? Nat. Rev. Neurosci. 3, 715-727. http://dx.doi.org/10.1038/nrn919.

Palop, J.J., Lennart, M., 2010. Synaptic depression and aberrant excitatory network activity in Alzheimer's disease: two faces of the same coin? Neuromol. Med. 12, 48-55. http://dx.doi.org/10.1007/s12017-009-8097-7.

Paula-Lima, A.C., De Felice, F.G., Brito-Moreira, J., Ferreira, S.T., 2005. Activation of GABAA receptors by taurine and muscimol blocks the neurotoxicity of $\beta$-amyloid in rat hippocampal and cortical neurons. Neuropharmacology 49, 1140-1148. http:// dx.doi.org/10.1016/j.neuropharm.2005.06.015.

Paxinos, G., Watson, C., 2007. The Rat Brain. Academic Press, London, UK.

Rissman, R.A., De Blas, A.L., Armstrong, D.M., 2007. GABAA receptors in aging and Alzheimer's disease. J. Neurochem. 103, 1285-1292. http://dx.doi.org/10.1111/j. 1471-4159.2007.04832x.

Southam, K.A., Vincent, A.J., Small, D.H., 2016. Do microglia default on network maintenance in Alzheimer's disease? J. Alzheimer's Dis. 51, 657-669. http://dx.doi. org/10.3233/JAD-151075.

Swartzwelder, H.S., Tilson, H.A., McLamb, R.L., Wilson, W.A., 1987. Baclofen disrupts passive avoidance retention in rats. Psychopharmacology 92, 398-401. http://dx.doi. org/10.1007/BF00210851.

Tritsch, N.X., Granger, A.J., Sabatini, B.L., 2016. Mechanisms and functions of GABA corelease. Nat. Rev. Neurosci. 17, 139-145. http://dx.doi.org/10.1038/nrn.2015.21.

Trovato-Salinaro, A., Siracusa, R., Di Paola, R., Scuto, M., Fronte, V., Koverech, G., Luca, M., Serra, A., Toscano, M.A., Petralia, A., Cuzzocrea, S., Calabrese, V., 2016. Redox modulation of cellular stress response and lipoxin A4 expression by Coriolus versicolor in rat brain: relevance to Alzheimer's disease pathogenesis. Neurotoxicology 53, 350-358. http://dx.doi.org/10.1016/j.neuro.2015.09.012.

Verkhratsky, A., Zorec, R., Rodríguez, J.J., Parpura, V., 2016. Astroglia dynamics in ageing and Alzheimer's disease. Curr. Opin. Pharmacol. 26, 74-79. http://dx.doi.org/ 10.1016/j.coph.2015.09.011.

Warren, J.D., Rohrer, J.D., Schott, J.M., Fox, N.C., Hardy, J., Rossor, M.N., 2013. Molecular nexopathies: a new paradigm of neurodegenerative disease. Trends Neurosci. 36, 561-569. http://dx.doi.org/10.1016/j.tins.2013.06.007.

Yoon, B.-E., Lee, C.J., 2014. GABA as a rising gliotransmitter. Front. Neural Circuits 8 , 141. http://dx.doi.org/10.3389/fncir.2014.00141.

Zemankovics, R., Veres, J.M., Oren, I., Hájos, N., 2013. Feedforward inhibition underlies the propagation of cholinergically induced gamma oscillations from hippocampal CA3 to CA1. J. Neurosci. 33, 12337-12351. http://dx.doi.org/10.1523/JNEUROSCI 3680-12.2013. 